
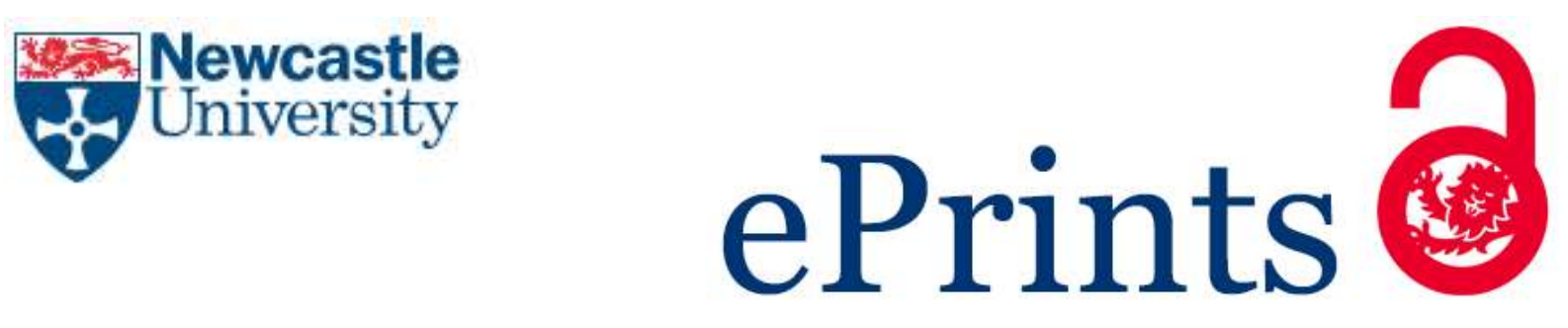

\author{
Forestieri A, Arnone E, Blenkinsop S, Candela A, Fowler H, Noto LV. \\ The impact of climate change on extreme precipitation in Sicily, Italy. \\ Hydrological Processes 2018, \\ https://doi.org/10.1002/hyp.11421
}

\title{
Copyright:
}

This is the peer reviewed version of the following article: Forestieri A, Arnone E, Blenkinsop S, Candela A, Fowler $\mathrm{H}$, Noto LV. The impact of climate change on extreme precipitation in Sicily, Italy. Hydrological Processes 2018, which has been published in final form at https://doi.org/10.1002/hyp.11421. This article may be used for non-commercial purposes in accordance with Wiley Terms and Conditions for SelfArchiving.

DOI link to article:

https://doi.org/10.1002/hyp.11421

Date deposited:

$16 / 01 / 2018$

Embargo release date:

17 December 2018 


\section{The impact of climate change on extreme precipitation in Sicily, Italy}

A. Forestieri ${ }^{1}$, E. Arnone ${ }^{2,3}$, S. Blenkinsop ${ }^{4}$, A. Candela ${ }^{2}$, H. Fowler ${ }^{4}$, L.V. Noto ${ }^{2}$

[1] CIMA Research Foundation, Via Armando Magliotto, 2 - 17100 Savona. Italy

[2] Dipartimento di Ingegneria Civile, Ambientale, Aerospaziale, dei Materiali, Università degli Studi di Palermo, Viale delle Scienze, Edificio 8, 90128, Palermo, Italy

[3] AMIGO s.r.l., Via Flaminia 48, I-00196, Roma, Italy

[4] School of Civil Engineering and Geosciences, Newcastle University, Cassie Building, Newcastle Upon Tyne, NE1 7RU, UK

Corresponding author: forestieri.angelo@gmail.com 


\section{Abstract}

Increasing precipitation extremes are one of the possible consequences of a warmer climate. These may exceed the capacity of urban drainage systems and thus impact the urban environment. Since short-duration precipitation events are primarily responsible for flooding in urban systems it is important to assess the response of extreme precipitation at hourly (or sub-hourly) scales to a warming climate.

This study aims to evaluate the projected changes in extreme rainfall events across the region of Sicily (Italy) and, for two urban areas, to assess possible changes in Depth-Duration-Frequency (DDF) curves. We used Regional Climate Model (RCM) outputs from EURO-CORDEX ensemble simulations at a $\sim 12 \mathrm{~km}$ spatial resolution, for the current period and two future horizons under the Representative Concentration Pathways (RCPs) 8.5 scenario. Extreme events at the daily scale were first investigated by comparing the quantiles estimated from raingauge observations and RCM outputs. Secondly, we implemented a temporal downscaling approach to estimate rainfall for subdaily durations from the modelled daily precipitation and, lastly, we analyzed future projections at daily and sub-daily scales. A frequency distribution was fitted to annual maxima time series for the sub-daily durations to derive the DDF curves for two future time horizons and the two urban areas. The overall results showed a raising of the growth curves for the future horizons, indicating an increase in the intensity of extreme precipitation, especially for the shortest durations. The DDF curves highlight a general increase of extreme quantiles for the two urban areas, thus underlining the risk of failure of the existing urban drainage systems under more severe events.

Keywords: Climate change, extreme precipitation, DDF, temporal downscaling, EURO-CORDEX, RCM 


\section{Introduction}

Floods arising from extreme rainfall events are one of the most costly and dangerous natural hazards worldwide (Hallegatte et al., 2013; Knapp et al., 2008). Understanding and quantifying potential changes to the magnitude of extreme rainfall is thus fundamental for the design of urban hydraulic systems and flood assessments. Specifically, observations of annual maximum rainfall (AMR) events are necessary to derive Depth-Duration-Frequency (DDF) curves, which, in turn, are used for the hydrological design of flood control infrastructure and water management systems. The DDF curves, or intensity-duration-frequency (IDF) curves, are usually developed by fitting a theoretical distribution to the AMR at different sub-daily and sub-hourly durations. Therefore, understanding the possible future changes in short-duration rainfall might enable quantification of how DDF curves may consequently change and the possible effects on urban hydrology.

Evidence of positive trends in observed extreme rainfall has been demonstrated by several studies for daily and sub-daily timescales (Adamowski et al., 2010; Brunetti et al., 2000; Burn et al., 2011; Villarini et al., 2011; Min et al., 2011; Alexander et al., 2006; Arnone et al., 2013; Wang et al., 2013; Bonaccorso and Aronica, 2016). The Mediterranean area has been demonstrated to be one of the regions most affected by changes in climate, indicated as one of the major 'hot-spots' in future climate projections (Giorgi, 2006). Works on historical observations have demonstrated that in some areas sub-daily extreme rainfall is intensifying more rapidly than daily extreme precipitation (e.g., Lenderink and van Meijgaard, 2008; Arnone et al., 2013; Bonaccorso and Aronica, 2016; Burn et al., 2011; Berg et al., 2013), with possible consequences for the increased occurrence of flash floods caused by short-duration rainfall (Pumo et al., 2016, Forestieri et al., 2016) though this pattern is not observed in all locations (Barbero et al., 2017).

Precipitation extremes associated with particular dynamical regimes or particular precipitation types may respond differently to climate warming (O’Gorman, 2015). In particular, sub-daily extremes are dominated by convective precipitation which tends to be both of short-duration and spatially localized (Chan et al., 2014). It is then clear that quantifying and modeling the impacts of 
climate change on short duration rainfall remains an open and arduous challenge (Nguyen et al., 2010; Olsson et al., 2012; Arnbjerg-Nielsen et al., 2013; O’Gorman, 2015; Westra et al., 2014).

Products at finer resolution than those of Global Climate Models (GCMs) can be derived from Regional Climate Models (RCMs), which typically operate at 10-50 km and are driven through nested regional climate modeling. Studies based on both GCMs and RCMs indicate that the Mediterranean area will face a significant warming and summer precipitation decrease (e.g., Faggian and Giorgi, 2009; Giorgi and Lionello, 2008). In particular, Faggian and Giorgi (2009) evaluated the projection of future climate change over the Italian greater alpine region by using 20 GCMs but at very coarse resolution (i.e., $\sim 200 \mathrm{~km}$ ). They found a decrease in mean annual precipitation over the period 19902100 , with a more pronounced reduction over Italy, but indicated the need for higher resolution climate models. Similarly, Faggian (2015) evaluated climate change projections over the Mediterranean region, and in particular for Italy, using products derived from 10 RCMs at $\sim 25 \mathrm{~km}$ spatial resolution. The study confirmed the uncertainties which characterize model simulation of climate change over complex orography; specifically, the author indicated that the models' performances depend on the variable considered and/or the region investigated. The ability of current $\mathrm{RCM}$ simulations at different spatial resolutions (i.e., from 12 to $50 \mathrm{~km}$ ) to reproduce the main features of the Mediterranean climate was also evaluated by Panthou et al. (2016). The RCM simulations of heavy precipitation showed a significant bias with the observations at $25 \mathrm{~km}$, both in terms of spatial patterns and values, and they also found a general over-estimation of extreme return levels of daily precipitation. As an example, outputs from four combinations of GCMs and RCMs from the ENSEMBLES project, were used by Piras et al. (2014) to force a hydrological model and evaluate the induced effects on hydrological processes over a catchment in Sardinia (Italy). A crucial step for their application was the bias-correction and downscaling procedure in space and time to create high-resolution products which clearly increases the projection uncertainties.

Both GCMs and RCMs are based on 'convective' parameterization schemes to describe the average effects of convection. This is a simplified scheme that introduces model errors in the 
simulation of short duration precipitation extremes (Fowler and Ekström, 2009; Hanel and Buishand, 2010). Very high-resolution models, known as 'convection-permitting' models (CPMs), are needed to describe the convection explicitly, thus simulating large storms and mesoscale convective organization (Kendon et al., 2017). Convection-permitting models have now been run at climate length scales over many regions (Tabari et al., 2016; Kendon et al., 2014; 2017; Ban et al., 2015) and have many advantages in comparison to coarser resolution RCMs (Prein et al., 2015). The first CPM at climate length scales run for a future climate was at a resolution of $1.5 \mathrm{~km}$ over Southern England (Kendon et al., 2014; 2016). To date, CPM models (i.e. <4 km) are only available for limited regions of Europe, and do not provide full coverage of Italy, although a full Europe CPM run is underway with results expected in 2018 (Saeed et al., 2017; Tabari et al., 2016).

Products of the Coordinated Regional Climate Downscaling Experiment (CORDEX) (Giorgi et al., 2009) are available at $\sim 12 \mathrm{~km}$ spatial resolution for the whole Europe area (EURO-CORDEX), which allows for the simulation of daily rainfall. The climate projection framework within CORDEX is based on the set of new global model simulations in support of the IPCC Fifth Assessment Report (referred to as CMIP5). In order to estimate future changes in the sub-daily precipitation not covered by the high-resolution models (e.g. Italy), a temporal downscaling from the daily products is thus needed.

Several approaches for statistical temporal downscaling of precipitation time series have been suggested, including methods based on a point-process model (e.g., Glasbey et al., 1995; Koutsoyiannis and Onof, 2001; Marani and Zanetti, 2007). The disaggregation methodology developed by Koutsoyiannis and Onof (2001) generates hourly data from given daily totals using the Bartlett-Lewis model. Shahabul Alam and Elshorbagy (2015) used the K-nearest neighbor (K-NN) technique to disaggregate daily precipitation generated with a stochastic rainfall generator to hourly and sub-hourly scales and thus evaluate the climate induced changes on DDF curves. Srivastav et al. (2014) proposed the use of the Equidistance Quantile Matching (EQM) methodology (also known as quantile-quantile mapping) as a downscaling method for GCM data (Singh et al., 2016; Lehmann et 
al., 2016; Simonovic et al., 2016). The idea of this method is to apply a bias-correction derived from the differences between observed data and GCM/RCM outputs for a baseline period (quantile mapping functions), which are then used to modify the GCM/RCM outputs in future periods, from which DDF curves are then calculated. The quantile-mapping functions are directly applied to AMR to establish the statistical relationships between AMRs for GCM generated daily precipitation data and observed daily and sub-daily data. Other possible approaches are based on the use of statistical weather generators capable of reproducing time series of weather variables, including precipitation, by preserving the internal structure of the precipitation process, the observed statistical properties and, in the case of GCM projections, the changes in GCM values between the projection horizon and observed period (Walsh, 2011). With respect to modeling complexities and uncertainty, the downscaling method based on the quantile-quantile mapping procedure is relatively simple and computationally efficient (Simonovic et al., 2016).

The climate scenarios and related changes in rainfall statistics have been transferred to changes in flood frequencies of sewer systems and overflow frequencies of storage facilities. It is clear that this might have a significant impact on future urban water management and planning, and some adaptation strategies will be required (e.g. Semadeni-Davies et al., 2007; Willems, 2013; Dale et al., 2017; Neumann et al., 2015).

In this study we focus our analysis on the Mediterranean island of Sicily (Italy), where the evidence of statistically significant trends of extreme rainfall at daily and sub-daily have been demonstrated in the past by Aronica et al. (2002), Arnone et al. (2013) and more recently by Bonaccorso and Aronica (2016). The research has been focused on two specific urban areas. Different studies have designed and developed Regional Frequency Analysis (RFA) procedures to estimate the parameters of DDF curves at the regional scale (e.g., Cannarozzo et al., 1995; Lo Conti et al., 2007). More recently, Forestieri et al. (2017) have proposed an updated RFA for Sicily which provided a different classification of statistically homogeneous regions based on the identification of the most representative statistical distribution of the rainfall characteristics. 
On the basis of this latest proposed regionalization, here we investigate how we might reliably quantify the impact of climate change on sub-daily extreme precipitation over the Mediterranean island of Sicily (Italy) starting from RCM daily products, and how the DDF curves across two main metropolitan areas of the island, i.e. Palermo and Catania, may consequently change in the future. The two selected areas are representative of two different climatic zones of the island and the applied methodology could be implemented in the future to the entire region. We use model outputs from the Coordinated Regional Climate Downscaling Experiment for Europe area (EURO-CORDEX) at 12 $\mathrm{km}$ spatial resolution to (i) investigate the capability of the RCMs to reproduce daily extreme precipitation for Sicily; (ii) estimate the projected changes across Sicily and the two urban areas by evaluating the impact of climate change on the daily and sub-daily projection series and extremes for two sequential future time horizons; and (iii) estimate updated DDF curves at two stations located in Palermo and Catania and consider the possible impacts on urban hydrology.

\section{Study Area and Data}

Sicily is situated in the south of Italy and is the largest island in the Mediterranean Sea, with an area of approximately $25.000 \mathrm{~km}^{2}$ (Figure 1a). The locations of the two main metropolitan areas of Sicily are also shown in Figure 1a. Palermo is located on the north coast of Sicily, facing the Tyrrhenian Sea; the urban area comprising a population of $\sim 850,000$, its metropolitan area the fifth most populated in Italy. Catania faces the Ionian Sea on the east coast of Sicily, the population of the central urban area estimated at $\sim 315,000$.

The orography of the island is highly variable, with elevation ranging from 0 to $3320 \mathrm{~m}$ a.s.1. in the eastern part of the region. Precipitation over the region is influenced by elevation and thus is characterized by significant spatial variability. The spatial distribution of mean annual precipitation (MAP) is shown in Figure $1 \mathrm{~b}$ (from Di Piazza et al., 2011) indicating a minimum of $\sim 360 \mathrm{~mm}$ in the south-east and maximum of $\sim 1900 \mathrm{~mm}$ in the north-east, with an overall mean of $\sim 700 \mathrm{~mm}$. The two selected areas are characterized by slightly different average MAP. Rainfall may be characterized by 
a summer and winter season, with rainfall mostly concentrated in the winter season (i.e., from November to March) whereas July and August are usually rainless (Viola et al., 2017). The mean annual temperature ranges from $11^{\circ} \mathrm{C}$ to $20^{\circ} \mathrm{C}$ (Di Piazza et al., 2011).

\subsection{Gauge-rainfall observations}

Rainfall data have been retrieved from the local hydrological observatory database managed by Osservatorio delle Acque, Regione Sicilia (hereinafter OA). For the purposes of this work, two types of data were needed: the daily rainfall totals (DR), from which the annual maximum daily rainfall were derived, and the annual maxima at durations of $1,3,6,12$, and $24 \mathrm{~h}\left(\mathrm{AMR}^{\mathrm{d}}\right)$ which, hereafter, will be referred to as sub-daily. The OA raingauge network consists of a total of 314 stations, with rainfall records starting from 1928; a full description of the dataset with statistical details of rainfall properties are provided by Arnone et al. (2013) and Di Piazza et al. (2011). Currently, sub-hourly rainfall data are not available from this database (Caracciolo et al., 2017).

For this work, the selection of raingauges and historical period of observation was constrained by the availability of the corresponding RCM outputs (see section 2.2). Overall, daily rainfall totals were retrieved from 214 raingauges for the period 1972-2003, corresponding to the control simulation for RCMs as explained in the next section (Figure $1 \mathrm{~b}$ ), whereas $\left(\mathrm{AMR}^{\mathrm{d}}\right.$ ) were retrieved from 114 raingauges for the period 1972-2003 (Figure 1b). Each station has a minimum record length of 20 years. The same $A M R^{d}$ dataset was used by Forestieri et al. (2017) to carry out an updated regional frequency analysis (RFA).

\subsection{EURO-CORDEX data}

The CORDEX framework (http://wcrp-cordex.ipsl.jussieu.fr/, Giorgi et al. 2006) is an internationally coordinated framework developed to provide multi-model ensembles of regional climate projections for land regions worldwide. The EURO-CORDEX (http://www.euro-cordex.net) project is part of the global framework and provides regional climate simulations for the European 
domain at $0.44^{\circ}$ on a rotated grid (EUR-44), corresponding to $\sim 50 \mathrm{~km}$, and $0.11^{\circ}$ on a rotated grid (EUR-11), corresponding to $\sim 12 \mathrm{~km}$ resolution. Projections are downscaled from the latest generation CMIP5 global climate projections (Taylor et al., 2012) and under the new Representative Concentration Pathways (RCPs). The products of the regional simulations are at a daily resolution.

In this study, we used both 'control' simulations, i.e., simulations relative to an historical period, necessary to validate and assess the products, and future projections under the highest anthropogenic forcing scenario - the RCP8.5 pathway. We analyzed the 30-year time slice 1972-2003 as the control period to correspond with the raingauge observations, and two future projection horizons, i.e., 20052050 and 2050-2100. An ensemble of climate models is generally considered to evaluate the modelling uncertainty. Here we used 11 regional simulations as summarised in Table 1.

\section{Methods}

RCM outputs are typically affected by systematic and random model errors (Terink et al., 2008), therefore procedures of bias correction are often necessary to improve the reproduction of observed climate statistics. This is useful particularly in areas where the inter-annual variability is correctly represented but the biases are different for wet seasons and dry seasons, so often the RCMs tend to overestimate the number of wet days and thus total precipitation is also overestimated (Dosio, 2016). In order to reduce this 'drizzle effect', the RCM daily precipitation outputs were modified so that the monthly frequency of rain days matched that of the observed record.

In this study, we adopted a bias-adjustment technique based on the quantile-quantile mapping transformation developed by Boé et al. (2007) and Piani et al. (2010b), and widely used to correct and downscale RCM precipitation outputs (e.g., Dosio and Paruolo, 2011; Gudmundsson et al., 2012; Piani et al., 2010a). This methodology is here used to correct the simulated precipitation for the control period and future projections, and to downscale precipitation from daily to hourly timescales.

Operatively, we used the R-package 'qmap' for Statistical Transformations for Post-Processing Climate Model developed by Gudmundsson, 2016 (https://cran.r- 
project.org/web/packages/qmap/qmap.pdf).

The results of the corrected RCM products and their ability to reproduce historical rainfall characteristics were analyzed in terms of growth curves at a given duration in particular for the two selected metropolitan areas.

\subsection{Quantile-quantile mapping}

The quantile-quantile mapping transformation (QM) developed by Boé et al. (2007) and Piani et al. (2010b), is based on the calculation of a monotonically increasing transfer function (TF) such that the marginal cumulative distribution function (CDF) of the adjusted variable matches that of the observations. In other terms, the TF is a statistical transformation that allows a translation of the CDF of the RCM variable into the $\mathrm{CDF}$ of the local scale climate variable (quantile-quantile relation). A common assumption of most bias correction methods is stationarity, or time invariance, of the model errors. This implies that the empirical relationships in the correction algorithm and its parameterization for current climate conditions do not change over time and are also valid for future conditions. In general, the statistical transformation can be formulated as:

$$
P_{o b s}=T F\left(P_{R C M}\right)
$$

where $P_{o b s}$ indicates the precipitation from the historical observed dataset and $P_{R C M}$ the precipitation from the corresponding simulated RCM dataset. If the probability distribution of the variables is known, the transformation can be written as:

$$
P_{o b s}=F_{o b s}^{-1}\left(F_{R C M}\left(P_{R C M}\right)\right)
$$

where $F_{o b s}^{-1}$ is the inverse CDF corresponding to $P_{o b s}$ and $F_{R C M}$ is the CDF of $P_{R C M}$. The target of this approach is then to find the arbitrary function that may approximate the transformation. 
According to Piani et al. (2010b) and Boé et al. (2007), the statistical transformation can be both parametric and non-parametric functions. In the case of parametric transformations (Piani et al., 2010b), the quantile-quantile relation can be expressed by using two or more parameter relations, commonly linear, exponential or power (Gudmundsson et al., 2012; Piani et al., 2010a; Piani et al., 2010b; Dosio and Paruolo, 2011). All parametric TFs are fitted to the fraction of the CDF corresponding to observed non-zero values, i.e. to the observed wet days. This procedure was applied for each cell by setting the precipitation equal to zero for any day with precipitation lower than a transformation, the TF is formulated as follows:

$$
P_{R C M, c o r}=a+b\left(P_{R C M}\right)
$$
datasets are characterized by the following:

where $P_{R C M \text {,cor }}$ denotes the corrected precipitation from RCM model and $a$ and $b$ are the parameters of the TF which are estimated by solving eq. (2).

In order to estimate the parameters, the dataset is organized so that each RCM cell grid corresponds to one selected raingauge (Piani et al., 2010b). Therefore, values of each of the two datasets can be univocally identified throughout the geographic coordinates of the grid point of RCMs and observations, i.e., longitude, $\varphi$, and latitude, $\theta$, and the recording data, i.e. day, month and year indicated as $d, m$ and $y$, respectively. According to Piani et al. (2010), TF parameters can be estimated monthly, and therefore, data at each grid point can be sorted by precipitation depth so that the two 
where $i$ is the index value so that $P_{R C M}(\varphi, \theta, m, i+1) \geq P_{R C M}(\varphi, \theta, m, i)$ within each month and for the entire dataset.

Instead of assuming parametric distributions, the TF can also be derived using the empirical CDF of observed and modelled values (e.g., Boé et al., 2007; Themeß1 et al., 2012), which constitutes parametric or non-parametric transformations. The parametric transformations can be achieved by using simple theoretical distributions (e.g., linear, exponential), whereas in the case of nonparametric transformations, the function is derived based on the empirical CDF of observed and modelled values evaluated at regularly spaced quantiles (Gudmundsson et al. (2012), instead of assuming parametric distributions. Values in between the percentiles are approximated using linear interpolation.

In order to identify the best TF, we applied and compared the parametric linear transformation (PAR-LIN) and the non-parametric transformation function (QUANT) based on the quantile mapping. Overall performance for each RCM was measured using the spatial mean absolute error (MAE) between the observed and the corrected modelled value of the daily precipitation.

\subsection{Temporal downscaling}

The methodology based on the quantile-quantile mapping approach was also used to perform a temporal downscaling of daily precipitation to the hourly scale, following Srivastav et al. (2014), who proposed the use of the method for updating DDF curves under climate change.

It is based on the observed correlation between extreme rainfall at different subsequent durations, i.e. daily-24h, $24 \mathrm{~h}-12 \mathrm{~h}, 12 \mathrm{~h}-6 \mathrm{~h}$, etc. by assuming that this correlation remains invariant in the future. Given the annual maxima daily and sub-daily observed rainfall values, a non-parametric transfer function can be estimated according to the quantile-quantile mapping approach for each temporal step down to $1 \mathrm{~h}$. The five TFs, obtained by a comparison of the empirical CDF for each station, are evaluated from the pairs of data relative to different durations, e.g. daily-24h, $24 \mathrm{~h}-12 \mathrm{~h}$, etc. The process of temporal downscaling thus follows a "cascade method": the $24 \mathrm{~h}$ maxima dataset is 
obtained from daily data through a TF; $12 \mathrm{~h}$ maxima are generated from $24 \mathrm{~h}$ maxima data previously obtained and so on until the lowest duration of $1 \mathrm{~h}$ maxima.

As for the bias correction method, the procedure was applied to both control and future projections of rainfall from each RCM.

\subsection{Regional frequency analysis and DDF curves}

The analysis of extreme rainfall events was conducted by following a RFA procedure as presented by Forestieri et al. (2017), who provided up-to-date growth curves and index value parameter maps for the estimation of precipitation quantiles in Sicily. The authors introduced a new classification of statistical homogenous climate zones (or regions) for Sicily, which were identified based on a more complete analysis that includes several auxiliary variables.

The configuration of the regions is depicted in Figure 2, which classifies Sicily into six statistically homogenous zones, specifically two in the central area, i.e., centre north $(\mathrm{CN})$ and centre south (CS), three in the northern area, i.e., north central (NC), north east (NE) and north west (NW) and, finally, one in the southern area, i.e., south east (SE). The number of rain gauges in each region ranges from $63(\mathrm{CN})$ to $23(\mathrm{NE})$ for daily data and $34(\mathrm{CN})$ to $10(\mathrm{NE})$ for hourly data; however, the regions with the lowest gauge density are CS and SE. It should therefore be noted that a low number of stations could provide a greater uncertainty in the growth curve estimates when compared to regions with a higher number of stations (Forestieri et al., 2017).

As in Cannarozzo et al. (1995), Lo Conti et al. (2007), and Forestieri et al. (2017), we followed the index flood method, which involves the estimation of the growth curves and index values by using a hierarchical regional approach with different spatial aggregation levels. Among the different probability distributions investigated by Forestieri et al. (2017), we selected the three parameter LogNormal (LN3) distribution, which provides the best compromise between best fitting and overparameterization. The L-moments approach (Hosking and Wallis, 2005) was used to estimate the parameters of the distribution. 
For the two main metropolitan areas, Palermo and Catania (Figure 1a), we analyzed the DDF curves, which have been derived from both the observed data and the future projections of precipitation, in order to examine how the expected changes in hourly rainfall extremes (section 4.2) may affect the DDFs. The choice of these urban areas, characterized by different meteorological characteristics, allows the evaluation of the behaviour of the RCMs under different climate conditions. Palermo is influenced by the Tyrrhenian Sea and low-pressure rain-bearing systems from the north, while Catania, facing the Ionian Sea, is affected by low-pressure systems from the southwest that interact with the orography in the proximity of the coast, generating heavier precipitation.

The 'historical' DDFs were derived starting from the observed AMR series recorded by the two selected meteorological stations located in the Palermo and Catania areas (Figure 1), which lie within the $\mathrm{CN}$ and NE regions respectively (Figure 2). For Palermo, data from the raingauge at 'Osservatorio Astronomico' (coordinates UTM ED50, Est=355462; Nord=4219404) were selected, since they are characterized by the longest recording length, while the only station with hourly data available for Catania was at 'Istituto D'Agraria' (coordinates UTM ED50, Est=506400; Nord=44152468). The quantiles were estimated at given durations (d), i.e., 1, 3, 6, 12 and 24 hours, and return periods (T), i.e. 5, 10, 50 and 100 years. With regard to the future DDF curve, the same procedure was applied to the AMR series estimated from the RCMs outputs after the bias correction and temporal downscaling processes.

\section{Results}

\subsection{RCM post-processing: bias correction}

A preliminary analysis of the uncorrected RCM data is given in Figure 3, which shows, for each climate model, the spatial distribution of the index $r 95 p$ [\%], defined as the percentage of total precipitation which exceeds the 95th percentile daily amount and evaluated for the observed period. The values of $r 95 p$ provide an indication of the contribution of extreme daily rainfall to total precipitation. All the models show a similar spatial distribution, with the highest values in the east 
part of the island, which is the area with the highest values of mean annual precipitation (see Figure 1b). This pattern is particularly extensive in RCMs $2,3,4,6$, for which the values of $\mathrm{r} 95 \mathrm{p}$ for the Catania area are much higher than those for Palermo.

The bias correction was applied to RCM data testing two different transformation functions, i.e. linear-parametric and non-parametric empirical quantile. The overall performance of the two transformation functions have been assessed by evaluating the mean absolute error (MAE), as suggested by several studies (Gudmundsson et al., 2012; Piani et al., 2010a; Piani et al., 2010b). The MAE gives a measure of how close the corrected empirical CDFs are to the observed empirical CDF. We quantified the transformation errors on a dataset different to that used for calibration. Therefore, the available daily precipitation datasets, of all the rain gauges and the RCMs, were split into two subsets relative to two periods, i.e. 1972-1987 and 1988-2003, used for calibration and validation, respectively.

Table 2 reports the total MAE, averaged across all stations and for each RCM, of the uncorrected values, and the corrected values using the PAR-LIN and QUANT transformations. In some cases, the bias correction does not produce improvements, e.g. for RCM3 and RCM10 where the MAE of the uncorrected precipitation is lower than the corrected ones for both the transformations. Only the PARLIN function produced precipitation values whose MAE is much higher than that from the uncorrected precipitation (RCM3). Overall, QUANT performed better than PAR-LIN in seven out of eleven cases. For this reason, the non-parametric transformation function was selected to correct the RCMs and to conduct the analysis of extremes. It is important to recall that these correction techniques are designed with the limited scope of adjusting the simulated climate variable such that its distribution (or some aspects of it) may match the distribution of observed values.

\subsection{Daily Extremes}

The results of daily extremes are analyzed in terms of growth curves, which plot the growth factor $h^{\prime}(T)$ (i.e., growth factor dimensionless quantile) as a function of the return period, $T$. The T-year 
growth factors (i.e. the T-year values of the cumulative distribution function of dimensionless data; furthermore, the term "growth curve" denotes a set of growth factors for different return periods) and precipitation quantiles are estimated using the L-moment-based index storm procedure (Hosking and Wallis, 2005).

Figure 4 shows the growth curves obtained before (a) and after (b) the bias correction for each of the six regions (Figure 2) for the current period, i.e., obtained with the historical data (i.e., 19732005). The grey shaded area marks the limits of the RCM ensemble, whereas the solid black lines denote the curve for the observed data. In the uncorrected charts, the variability of the RCM outputs is evident, and thus the uncertainty associated with them increases considerably with the return period.

RCM6 (NE) and RCM10 (CS, CN, NW) produce the highest and steepest growth curve in almost all the regions. In the NC region, variation across the estimated growth curves is more limited, whereas in the NE region the growth curve estimated with RCM6 varies significantly from the others, thus increasing the ensemble range. Indeed, the general behaviour of the growth curves estimated from the uncorrected RCMs with respect to the observed growth curve is regionally dependent and thus is slightly different for the two analysed metropolitan areas. This could also be related to the fact that the NE region is characterized by the least number of raingauges and has a particular orography. This region is characterised by mountains in proximity to the sea which often generates precipitation by orographic lift. Only in the NW region do all models overestimate the growth factors; this part of Sicily is the flattest area of the island which may affect the regional climate modeling. In regions SE and NE, most of the models underestimate the growth curve, whereas in the central part of Sicily the observed growth curve is more central in the ensemble range. The eastern regions are those with the steepest growth curves, denoting a higher variation with the return period. As a consequence of the above features, the variation of the growth curves across the Catania metropolitan area is higher than across Palermo.

Bias correction clearly leads to a decrease in the model ensemble uncertainty, with similar growth 
curves to the observations (Figure $4 \mathrm{~b}$ ) and thus a significant improvement. After bias correction the RCMs tend to slightly underestimate the growth coefficient for higher return periods in the southern and eastern part of Sicily (i.e., CS, SE and NE regions, which include the Catania metropolitan area) as well as for most of the models in the NC region. In the other regions, and thus for Palermo metropolitan area, the RCMs tend to slightly overestimate the growth curve for long return periods.

In order to quantitatively evaluate the matching between the observed and the RCM-derived quantiles as well as the improvement introduced by the bias correction method, we determined the statistics reported in Figure 5 in terms of (a) bias, i.e. the mean of the differences between simulated and observed values of the variable, and (b) Root Mean Square Error (RMSE) as a function of the return period. Specifically, these statistics were evaluated over each of the six regions by computing the median among the $11 \mathrm{RCMs}$ and the mean across the stations belonging to each region. This indicates that the uncorrected RCM simulations lead to a significant overestimation of the quantiles in $\mathrm{NC}, \mathrm{NW}, \mathrm{CN}$, and $\mathrm{CS}$, as the return period increases, especially in the $\mathrm{NW}$ region. In the other two regions located in the eastern part of the island (SE and NE), the bias indicates that the models underestimate the quantiles. After correction, the bias is clearly reduced, with CS and NC subsequently characterized by smaller bias. Figure 5 b provides the corresponding RMSE, before and after correction; in this case, one can observe that NW and NE benefit most from the correction. The RMSE is significantly reduced especially for very long return periods; for example, at 100 years, for the NW and NE, it varies from $~ 1.5$ (before correction) to less than 0.25 (after correction), denoting the effectiveness of the methodology. In all regions, the RMSE of the corrected series is less than 0.5, even for long return periods.

Overall, the analysis of the growth curves for the current period indicates that the RCMs, after the appropriate correction, are able to reasonably reproduce the variation with the return period of the quantiles at the daily timescale.

Figure 6 shows the growth curves obtained from the RCM projections under climate scenario RCP 8.5 for the future horizons 2005-2050 (a) and 2050-2100 (b). The TFs previously identified were 
re-applied to the simulated precipitation for the two future horizons to correct the data, assuming that the TF correction factors are stationary. Hereinafter, we will analyze only the corrected RCM data by omitting the 'corrected' term for brevity.

Figure 6a shows that for 2005-2050 almost all the RCMs project a general increase of daily precipitation. Specifically, the regions $\mathrm{NW}$ and $\mathrm{CN}$ (which include the Palermo area) are characterized by the lowest variation of growth curves across the RCMs ensemble; NW also exhibits the least variation with the return period. Again, this could be related to a combination of factors - the orography of this part of the island is less variable, the MAP is lower and less variable, and the number of rain gauges used for the correction. In both regions, all the model projections suggest a raising of the growth curves.

In the CS region (which includes part of Catania metropolitan area), the RCM estimates project either a rising or a lowering of the growth curves in the immediate future. In the NC region, only three RCM projections indicate a rise of the growth curve with the return period, with a significant variation in the case of RCM7. Finally, as for the current period, even the future projections of the RCMs indicate the steepest growth curves in the eastern part of Sicily, with the exception of RCM5 in region $\mathrm{NE}$.

These results thus demonstrate that the change (in time) of the growth curve in the future depends on the region but also that, overall, there is an increase in the steepness of the curve with return period in the future as well as an increase of the uncertainty. For some regions, these aspects are even more emphasized for the 2050-2100 time horizon (Figure 6b), particularly in regions NC, NW, CN, NE. Only projections for region SE (which includes part of the Catania area) indicate a reduced steepness and variation of the growth curves with the return period in the later period.

\subsection{Hourly extremes}

This section analyzes the results of the temporal downscaling, based on the quantile-quantile mapping method, which first derives sub-daily precipitation series from daily precipitation and 
secondly estimates the annual maximum precipitation at given durations, for both the current period and future RCM projections. The TF parameters have been estimated by making use of the historical observations relative to the period 1973-2005 and the corresponding RCMs simulations. The correlation between observed extreme rainfall at different subsequent durations (1972-2003), i.e. daily-24h, 24h-12h, 12h-6h, etc., was high, as demonstrated by values of the coefficients of determination between the annual maximum value of precipitation (Table 3), confirming the hypothesis of a strong correlation between pairs of the subsequent durations.

For the sake of clarity, Figure 7 reports the empirical cumulative probability distribution (ecdf) of the observed and simulated series for 1, 3, 6, 12 and 24 hours for one rain gauge and the corresponding grid cell in the metropolitan area of Palermo (a) and Catania (b). For Palermo, the subdaily annual maxima rainfall are well reproduced by the RCM ensemble, even if some extreme values are slightly underestimated over most accumulation periods. The ecdfs for Catania are to the right with respect to those of Palermo, denoting that, in this area, rainfall extremes are heavier, in accordance with past studies (Cannarozzo et al., 1995, Lo Conti et al., 2007). Here, the uncertainty associated with the RCMs is greater; most of the models underestimate the extreme values, although some models are able to capture the heaviest precipitation at a given duration. It is then evident that the proposed methodology for the temporal downscaling is able to capture the statistical relationship between the RCM data and the sub-daily historical data. As before, the estimated TF parameters were then applied to the future RCM projections in order to assess how sub-daily extremes are likely to change in the future. Ideally, urban drainage system design requires knowledge of rainfall depth intensity values over shorter durations (e.g. Carbone et al., 2005, Pereira et al., 2015), with daily or hourly data disaggregated to a shorter timestep using the statistical relationships between high temporal resolution and lower resolution records (e.g. Pereira et al., 2015). However, the lack of subhourly rainfall observations here did not allow such downscaling to higher resolutions.

Following the regional analysis described in section 3.3 and in Forestieri et al. (2017), we derived the growth curves for each homogenous region, each duration and for the two future projection 
horizons. For the sake of brevity, we report in Figure 8 the results obtained for 2050-2100 and for 1 hour (a) and 12 hours (b). In all regions, it is evident that the future projections lead to a raising and steepening of the growth curves as the return period increases. The regions $\mathrm{NC}, \mathrm{NW}$ and $\mathrm{CN}$ are characterized by a wider range of uncertainty although in all three cases this is a result of the 'outlier' curve produced by RCM4. Growth curves at 12 hour duration (i.e. longer durations) (Figure $8 b$ ) are characterized by slightly gentler slopes than those of 1 hour duration (i.e. shorter duration); this means that the growth curves tend to be more amplified for shorter durations. The ensemble range is also narrower and thus the uncertainty decreases at this longer duration.

\subsection{Changes in DDF curves}

Changes in the DDF curves are analyzed for the two selected raingauges within the metropolitan areas of Palermo and Catania (Figure 1a) for the two future horizons, 2005-2050 and 2050-2100.

Figure 9 shows the DDF curves at 5, 10, 50 and 100 year return periods derived from the historical data (solid black line and grey shaded areas) and from the downscaled RCM outputs (box plots), for the future horizon 2005-2050 and for Palermo (a) and Catania (b). For Palermo, the future scenario leads to a clear increase in intensities based on the RCM ensemble medians, with a relatively small range of uncertainty from the model ensemble. In terms of return period, the DDF curves of the future scenario approximately correspond to the current curves but at higher return periods; for example, the median of the future DDF curve at 5 years corresponds to the current one at 10 years. The same behaviour can be observed for other return periods. . The same behaviour can be observed for other return periods. The variability depicted by the interquartile range of the boxplots, ranges from a few $\mathrm{mm}$ at 5 years to about $20 \mathrm{~mm}$ at 100 years, denoting that, for this case, the RCM outputs project similar results. However, in some cases, there is strong variability in terms of low and high extremes (minimum and maximum whiskers), such as for the very short durations (i.e., 1, 3, 6 hours) at 50 and 100 years.

In the case of Catania (Figure 9b), the 'historical' DDF curves are slightly higher than those for 
Palermo, confirming that this part of the island is usually characterized by heavier precipitation. The DDF curves derived from the RCMs under the climate change scenario show a higher variability which significantly increases with duration and even more with return period. For all four return periods, the variation of the future quantiles with respect to the historical quantiles does not increase linearly with the duration, with higher increases at longer durations. In some cases, the quantiles obtained with some RCM models provided lower values than those obtained with the historical data, such as for 3, 6, and 12 hours at 10 years, 6, 12 and 24 hours at 50 years and 6 hours at 100 years. This could be due to the structural uncertainty associated with the regional climatic models, as well as the uncertainty derived from the temporal downscaling procedure. In terms of return period, the median of the DDF curves of the future scenario for return periods greater than 10 years exhibit a more significant increase compared to Palermo; for example, the future 50 year DDF curve corresponds to the current 500 year DDF curve (not shown) for all durations.

The same results are reported in Figure 10 for the future time horizon 2050-2100. As expected, the median of the DDFs derived from the model ensemble shows a greater increase from the historical period, especially in the case of Catania for 50 and 100 year return periods where the quantiles show greater variability as shown in the box plots. However, it simultaneously increases the variability among the model ensemble. In particular, the higher increases of the 100 year return period estimates for Catania (e.g., 12 and 24 hours) are also characterized by higher variability.

The corresponding changes of the ensemble median DDF curve with respect to the historical period are reported in Table 4, which summarizes the above results as representative of the two metropolitan areas considered here. The value of the percentage change provides an immediate quantitative evaluation of the future change projected by the RCMs. For low return periods (i.e., 5 and 10 years) the changes in Palermo are larger than in Catania for short durations, e.g., for $\mathrm{T}=1 \mathrm{yr}$ and $\mathrm{d}=1 \mathrm{hr}$ changes are $\sim+37 \%$ (2005-2050) and $\sim+39 \%$ (2050-2100) for Palermo compared with $\sim+18 \%$ and $\sim+27 \%$ respectively for Catania. For high return periods and longer durations, changes in Catania are significantly higher than those in Palermo, e.g., for $\mathrm{T}=100 \mathrm{yr}$ and $\mathrm{d}=24 \mathrm{hr}$ changes are 
$\sim+25 \%$ (2050-2100) for Palermo compared with +65\% for Catania; for the short durations but high return periods the changes are more or less similar.

The commonly used power-law function of type $H(d, T)=a d^{\wedge} n$, where $a$ and $n$ are sitespecific parameters, was fitted to the observed sub-daily quantiles at given return period and to the median of the sub-daily quantiles obtained from the RCM ensemble. The corresponding parameters are reported in Table 5, together with the changes of the parameters with respect to the historical DDFs. In the case of Palermo, parameter $a$, which is indicative of the quantile at the 1 hour duration, has a maximum increase of $68 \%$ (2050-2100), which occurs at the longest return period (100 years). The parameter $n$, which is indicative of the scaling of the quantile with duration, decreases by up to $24 \%$ (2050-2100), denoting a reduced variation of the quantile with duration for a given return period. For Catania, the increase in $a$ is up to $74 \%$ (2050-2100 at 100 years), which denotes a more considerable variation of the quantile at the shortest durations; whereas $n$ displays much lower changes of varying sign compared to Palermo.

The overall results indicate that for short durations the increase in extremes is greater than that for longer durations, thus suggesting the idea that the intensification of extreme events is more evident for short duration precipitation, usually associated with convective events. This is consistent with some previous research on the intensification of extreme rainfall in relation to a warming atmosphere. The Clausius-Clapeyron relation (CC) suggests that if relative humidity remains constant, atmospheric humidity will increase at a rate that follows the saturation vapour pressure dependency on temperature according to the CC relation - a rate of $\sim 7 \%$ per ${ }^{\circ} \mathrm{C}$ of surface warming (e.g. Allen $\&$ Ingram, 2002). Several studies have provided observational evidence of a $\sim 2 \mathrm{x}$ CC relationship for hourly extremes (e.g., Lenderink \& van Meijgaard, 2008, 2010, Mishra et al., 2012) which might suggest an amplified response to warming on these timescales and is consistent with the projections obtained here 


\section{Summary and Discussion}

This study has provided an insight into the potential impacts of climate change on extreme precipitation for the Mediterranean island of Sicily (Italy), starting from an ensemble of RCM simulations at the daily timescale. Changes in extremes clearly affect the shape of Depth Duration Frequency (DDF) curves, which are commonly used for the design of hydraulic infrastructure and thus normally adopted for urban planning policies. For this reason, understanding possible changes in heavy, short duration precipitation is necessary for the updating of DDF curves.

The spatial resolution of the available RCM outputs for the Mediterranean area does not currently provide precipitation products at a sub-daily scale from convection-permitting models, therefore a temporal downscaling procedure is needed to estimate the precipitation for short accumulations. In this study, the products of the Coordinated Regional Climate Downscaling Experiment for Europe (EURO-CORDEX) with $\sim 12 \mathrm{~km}$ spatial resolution were used to accomplish different targets. Specifically, the main results and outcomes can be summarized as follows:

(i) we demonstrated the capability of the available EURO-CORDEX RCM runs to reproduce extreme precipitation at the daily scale over Sicily. However, since precipitation in Sicily is strongly influenced by the highly variable orography (Di Piazza et al., 2011; Forestieri et al., 2017), a bias correction method was necessary to reduce the errors between observed and simulated precipitation as demonstrated by other studies in other Mediterranean areas (e.g., Dosio and Paruolo, 2011; Dosio, 2016; Piani et al., 2010a and 2010b). In particular, the non-parametric statistical transformation, based on the quantile method approach, provided successful results, allowing for a significant reduction of the bias between observed and simulated statistics, reducing the uncertainty range of the RCM ensemble despite both methods having theoretical limitations (White and Toumi, 2013). The efficiency of the bias correction method was linked to the use of statistically homogenous regions developed by Forestieri et al. (2017) which were used for the regional frequency analysis. The growth curves at a given durations (i.e. 1 day) were derived from observed and simulated annual maxima for the 'control period' and the results demonstrate that RCM output could be reliably used to estimate 
extremes at the daily scale in Sicily after bias correction.

(ii) We analyzed the impacts of climate change on the regional growth curves over two future projection time horizons, 2005-2050 and 2050-2100, and under the Representative Concentration Pathways (RCPs) 8.5 scenario by means of the corresponding RCM outputs. The overall results showed a steepening of the growth curves for the future climate, especially for 2050-2100, thus indicating an increase the intensity of extreme precipitation events. However, the results for some regions also indicated significant variability and thus uncertainty resulting from the RCM ensemble, which increases for the farthest future time horizon. Clearly, this is due to other sources of uncertainty such as those resulting from errors in the projections of the climate models themselves (Piani et al., 2010b).

(iii) To estimate the changes in sub-daily precipitation, we applied a temporal downscaling method based on the quantile-quantile matching approach, also used to correct the RCMs products. The matching between observed and modelled data was shown for two rain gauges, located in Palermo and Catania, in terms of AMR at different durations, demonstrating that the modelled series reproduced well the AMR, especially in the case of Palermo, although very extreme values were underestimated. An analysis of growth curves showed that the increase of the growth coefficient with return period is more evident for the shortest durations (1 hour). The lack of sub-hourly rainfall has restricted the analysis to the hourly time scale although in urban drainage systems sub-hourly rainfall is fundamental in the design stage.

(iv) For Palermo and Catania, we evaluated the impact of changes in extreme precipitation on the DDF curves. The results showed an increase in the quantiles at different durations, especially in case of the Catania urban area, which is characterized by higher annual maxima rainfall than Palermo and slightly higher mean annual precipitation. However, even in this case, the variability of the RCM projections was more substantial for the higher return periods and the longest future time horizon. Similar studies of DDFs (or IDFs), e.g. Srivastav et al. (2014), obtained comparable outcomes; however, they did not assess the uncertainty associated with the RCMs. Changes of the DDF curve 
parameters also indicated a significant increase of the quantile at the shortest duration (parameter $a$ ); and a tendency for a reduced variation of the quantile with duration at a given return period (parameter $n)$.

(v) The changes in the DDF curves may have important implications for the management of the existing urban hydraulic systems of the two analyzed areas as well as for the severity and the frequency of urban floods in the two cities. The shift of the DDF curves towards heavier extreme events may determine the infrastructure deficit of micro and macro drainage facilities that will consequently be undersized to meet future demands, as demonstrated also in other studies (e.g. Tucci and Collischonn, 2000). During heavy precipitation events, the water that flows in the pipe system returns to the street system if the capacity of the drainage system is insufficient, thus causing surface flooding. These dynamics are normally simulated through urban drainage models whose use in future works may allow us to evaluate the impacts on sewer surcharge and flooding of Palermo and Catania. Specifically, the DDF shift may modify the spatial distribution of the critical network nodes i.e. the nodes where water comes out from manholes, and a significant question may be how these changes will have an impact in terms of the number of failing drainage network nodes. What we can expect is then a decrease of the return period of the current drainage systems if no management changes are designed (as an order of magnitude, Willems, 2013 obtained a maximum variation from 20 to 5 years in a case study in Belgium). Finally, in the case of urban storage facilities, we may expect that extra storage capacity could be required (e.g., 10-40\%) (Willems, 2013). As a consequence of these possible future implications, two different strategies could be then adopted by the urban planners and designers, i.e. a programme of routine and scheduled replacement and renewal of ageing infrastructure, and/or the adoption of optimization methods for climate change adaptation (e.g. green infrastructure, SUDS) (Zhou et al., 2012). The overall results clearly provide an important indication of future precipitation extremes and the impact of climate change on extreme events. These results are in accordance with other studies which analyzed the potential implication of global warming on different Mediterranean areas, such as Deidda et al. (2013), Piras et al. (2014), Panthou et al. (2016), 
who indicated that, on daily and sub-daily time scales, heavy events are projected to become more frequent and more intense.

No assessment of projected changes in short-duration rainfall extremes for Sicily has previously been published to our knowledge. However, it is clear that our findings (as well as those of other studies) are affected by uncertainty associated with climate model errors and the use of convection parameterisation schemes, in addition to the temporal downscaling which is based on the assumption of stationarity of the transfer functions. The application of statistical tools for bias correction and disaggregation procedures however remains indispensable for reproducing sub-daily series whilst ensembles of CPM simulations are not available. Such sub-daily series are an important requirement when climate forcing for hydrological models has to be generated. In the specific case of Sicily, the climate and hydrological regime is also strongly related to the highly variable topographic characteristics, which may increase the sources of uncertainty. Because a full Europe convectivepermitting model (CPM) run is underway with results expected in 2018, a future extension of this work will involve the comparison of our findings with those obtained from higher resolution climate models.

\section{Conclusions}

This study has provided an overview of possible changes in extreme precipitation over Sicily, and in DDF curves for the two main metropolitan areas, induced by climate change, by using the outputs of an ensemble of RCMs. The consequent changes in the DDF curves showed that we may expect an intensification of extreme events, especially in the wetter east area of the island. As a possible consequence, an increase of severity and frequency of urban floods may be expected in the future, as well as a more frequent failure of the sewer system capacity if no appropriate management actions are taken. The procedure applied in this study provides a possible methodology which can be used to evaluate the potential changes in the DDF curves. Further applications in other locations represent a possible step of our research focusing on the urban drainage and flooding. Design and 
648 optimisation of urban drainage infrastructure that considers climate change impacts is a further, new 649 perspective for the future.

650

651

652

653

Acknowledgements

Stephen Blenkinsop and Hayley J. Fowler are funded by the European Research Council Grant, INTENSE (ERC-2013-CoG-617329. H.J.F. is also funded by the Wolfson Foundation and the Royal 654 Society as a Royal Society Wolfson Research Merit Award holder (WM140025). 
656

657

658

659

660

661

662

663

664

665

666

667

668

669

670

671

672

673

674

Allen MR, Ingram WJ, 2002, "Constraints on future changes in climate and the hydrologic cycle" Nature 419 224-232.

Adamowski, J., Adamowski, K., \& Bougadis, J. (2010). Influence of trend on short duration design storms. Water Resources Management, 24(3), 401-413.

Alexander, L. V., Zhang, X., Peterson, T. C., Caesar, J., Gleason, B., Klein Tank, A. M. G., ... \& Tagipour, A. (2006). Global observed changes in daily climate extremes of temperature and precipitation. Journal of Geophysical Research: Atmospheres, 111(D5).

Alam, M. S., \& Elshorbagy, A. (2015). Quantification of the climate change-induced variations in Intensity-Duration-Frequency curves in the Canadian Prairies. Journal of Hydrology, 527, 9901005.

Arnbjerg-Nielsen, K., Willems, P., Olsson, J., Beecham, S., Pathirana, A., Gregersen, I. B., ... \& Nguyen, V. T. V. (2013). Impacts of climate change on rainfall extremes and urban drainage systems: a review. Water Science and Technology, 68(1), 16-28.

Arnone, E., Pumo, D., Viola, F., Noto, L. V., \& La Loggia, G. (2013). Rainfall statistics changes in Sicily, Hydrol. Earth Syst. Sci., 17, 2449-2458, 10.5194/hess-17-2449-2013.

Aronica, G., Cannarozzo, M., \& Noto, L. (2002). Investigating the changes in extreme rainfall series recorded in an urbanised area. Water Science and Technology, 45(2), 49-54.

Ban, N., Schmidli, J. \& Schär C. (2015). Heavy precipitation in a changing climate: Does short-term summer precipitation increase faster? Geophys. Res. Lett., 42, 1165-1172, doi:10.1002/2014GL062588.

Barbero, R., Fowler, H.J., Lenderink, G. \& Blenkinsop, S. (2017). Is the intensification of precipitation extremes with global warming better detected at hourly than daily resolutions? Geophys. Res. Lett., 44, 974-983, doi:10.1002/2016GL071917.

Berg, P., Moseley, C., \& Haerter, J. O. (2013). Strong increase in convective precipitation in response to higher temperatures. Nature Geoscience, 6(3), 181-185. 
Blenkinsop, S., Jones, P. D., Dorling, S. R., \& Osborn, T. J. (2009). Observed and modelled influence of atmospheric circulation on central England temperature extremes. International Journal of Climatology, 29(11), 1642-1660.

Boé, J., Terray, L., Habets, F., \& Martin, E. (2007). Statistical and dynamical downscaling of the Seine basin climate for hydro - meteorological studies. International Journal of Climatology, 27(12), 1643-1655.

Bonaccorso, B., \& Aronica, G. T. (2016). Estimating temporal changes in extreme rainfall in Sicily region (Italy). Water Resources Management, 1-20.

Burn, D. H., Mansour, R., Zhang, K., \& Whitfield, P. H. (2011). Trends and variability in extreme rainfall events in British Columbia. Canadian Water Resources Journal, 36(1), 67-82.

Cannarozzo, M., D'asaro, F., \& Ferro, V. (1995). Regional rainfall and flood frequency analysis for Sicily using the two component extreme value distribution. Hydrological Sciences Journal, 40(1), $19-42$.

Caracciolo, D., Arnone, E., Conti, F. L., \& Noto, L. V. (2017). Exploiting historical rainfall and landslide data in a spatial database for the derivation of critical rainfall thresholds. Environmental Earth Sciences, 76(5), 222.

Carbone, M., Turco, M., Brunetti, G., Piro, P. (2015). A Cumulative Rainfall Function for Subhourly Design Storm in Mediterranean Urban Areas. Advances in Meteorology, 2015, 528564. doi:10.1155/2015/528564.

Chan, S. C., Kendon, E. J., Fowler, H. J., Blenkinsop, S., Roberts, N. M., \& Ferro, C. A. (2014). The value of high-resolution met office regional climate models in the simulation of multihourly precipitation extremes. Journal of Climate, 27(16), 6155-6174.

Chandra, R., Saha, U., \& Mujumdar, P. P. (2015). Model and parameter uncertainty in IDF relationships under climate change. Advances in Water Resources, 79, 127-139.

Climate Change Adaptation (2013). Recent cases. Danish Portal for Climate Change Adaptation. http://en.klimatilpasning.dk/recent/cases.aspx (accessed 20 February 2013). 
Dale, M., Luck, B., Fowler, H.J., Blenkinsop, S., Gill, E., Bennett, J., Kendon, E. \& Chan, S. (2017). New climate change rainfall estimates for sustainable drainage. Engineering Sustainability, 170, ES4, 214-224. doi:10.1680/jensu.15.00030.

Deidda, R., Marrocu, M., Caroletti, G., Pusceddu, G., Langousis, A., Lucarini, V., ... \& Speranza, A. (2013). Regional climate models' performance in representing precipitation and temperature over selected Mediterranean areas. Hydrology and Earth System Sciences, 17(12), 5041.

Di Piazza, A., Lo Conti, F., Noto, L. V., Viola, F., \& La Loggia, G. (2011). Comparative analysis of different techniques for spatial interpolation of rainfall data to create a serially complete monthly time series of precipitation for Sicily, Italy. International Journal of Applied Earth Observation and Geoinformation, 13(3), 396-408.

Dosio, A., \& Paruolo, P. (2011). Bias correction of the ENSEMBLES high - resolution climate change projections for use by impact models: evaluation on the present climate. Journal of Geophysical Research: Atmospheres, 116(D16).

Dosio, A. (2016). Projections of climate change indices of temperature and precipitation from an ensemble of bias - adjusted high - resolution EURO - CORDEX regional climate models. Journal of Geophysical Research: Atmospheres, 121(10), 5488-5511.

Faggian, P., \& Giorgi, F. (2009). An analysis of global model projections over Italy, with particular attention to the Italian Greater Alpine Region (GAR). Climatic Change, 96(1), 239-258.

Forestieri, A., Caracciolo, D., Arnone, E., \& Noto, L. V. (2016). Derivation of Rainfall Thresholds for Flash Flood Warning in a Sicilian Basin Using a Hydrological Model. Procedia Engineering, $154,818-825$.

Forestieri, A., Lo Conti, F., Blenkinsop, S., Cannarozzo, M., Fowler, H. J., \& Noto, L. (2017). Regional frequency analysis of extreme precipitation for Sicily (Italy). International Journal of Climatology (accepted).

Fowler, H. J., \& Kilsby, C. G. (2003). Implications of changes in seasonal and annual extreme rainfall. Geophysical Research Letters, 30(13). 
Fowler, H. J., \& Ekström, M. (2009). Multi - model ensemble estimates of climate change impacts on UK seasonal precipitation extremes. International Journal of Climatology, 29(3), 385-416.

Giorgi, F., Jones, C., \& Asrar, G. R. (2009). Addressing climate information needs at the regional level: the CORDEX framework. World Meteorological Organization (WMO) Bulletin, 58(3), 175.

Giorgi, F. (2006). Climate change hot - spots. Geophysical research letters, 33(8).

Giorgi, F., \& Lionello, P. (2008). Climate change projections for the Mediterranean region. Global and planetary change, 63(2), 90-104.

Glasbey, C. A., Cooper, G., \& McGechan, M. B. (1995). Disaggregation of daily rainfall by conditional simulation from a point-process model. Journal of Hydrology, 165(1-4), 1-9.

Gudmundsson, L., Bremnes, J. B., Haugen, J. E., \& Engen-Skaugen, T. (2012). Technical Note: Downscaling RCM precipitation to the station scale using statistical transformations-a comparison of methods. Hydrology and Earth System Sciences, 16(9), 3383-3390.

Hallegatte, S., Green, C., Nicholls, R. J., \& Corfee-Morlot, J. (2013). Future flood losses in major coastal cities. Nature climate change, 3(9), 802-806.

Hanel, M., \& Buishand, T. A. (2010). On the value of hourly precipitation extremes in regional climate model simulations. Journal of hydrology, 393(3), 265-273.

Hosking, J. R. M., \& Wallis, J. R. (2005). Regional frequency analysis: an approach based on Lmoments. Cambridge University Press.

Karl, T. R., \& Trenberth, K. E. (2003). Modern global climate change. science, 302(5651), 17191723.

Kendon, E. J., Roberts, N. M., Fowler, H. J., Roberts, M. J., Chan, S. C., \& Senior, C. A. (2014). Heavier summer downpours with climate change revealed by weather forecast resolution model. Nature Climate Change, 4(7), 570-576.

Kendon, E. J., Ban, N., Roberts, N. M., Fowler, H. J., Roberts, M. J., Chan, S. C., ... \& Wilkinson, J. M. (2017). Do convection-permitting regional climate models improve projections of future precipitation change?. Bulletin of the American Meteorological Society, (2016). 
Knapp, A. K., Beier, C., Briske, D. D., Classen, A. T., Luo, Y., Reichstein, M., ... \& Heisler, J. L. (2008). Consequences of more extreme precipitation regimes for terrestrial ecosystems. Bioscience, 58(9), 811-821.

Kotlarski, S., Keuler, K., Christensen, O. B., Colette, A., Déqué, M., Gobiet, A., ... \& Nikulin, G. (2014). Regional climate modeling on European scales: a joint standard evaluation of the EUROCORDEX RCM ensemble. Geoscientific Model Development, 7(4), 1297-1333.

Koutsoyiannis, D., \& Onof, C. (2001). Rainfall disaggregation using adjusting procedures on a Poisson cluster model. Journal of Hydrology, 246(1), 109-122.

Lafon, T., Dadson, S., Buys, G., \& Prudhomme, C. (2013). Bias correction of daily precipitation simulated by a regional climate model: a comparison of methods. International Journal of Climatology, 33(6), 1367-1381.

Lehmann, E. A., Phatak, A., Stephenson, A., \& Lau, R. (2016). Spatial modelling framework for the characterisation of rainfall extremes at different durations and under climate change. Environmetrics, 27(4), 239-251.

Lenderink, G., \& Van Meijgaard, E. (2008). Increase in hourly precipitation extremes beyond expectations from temperature changes. Nature Geoscience, 1(8), 511-514.

Lenderink G, van Meijgaard E. 2010. Linking increases in hourly precipitation extremes to atmospheric temperature and moisture changes, Environ. Res. Lett., 5(2), 025,208.Marani, M., \& Zanetti, S. (2007). Downscaling rainfall temporal variability. Water resources research, 43(9).

Min, S. K., Zhang, X., Zwiers, F. W., \& Hegerl, G. C. (2011). Human contribution to more-intense precipitation extremes. Nature, 470(7334), 378-381.

Mirhosseini, G., Srivastava, P., \& Stefanova, L. (2013). The impact of climate change on rainfall Intensity-Duration-Frequency (IDF) curves in Alabama. Regional Environmental Change, 13(1), 25-33.

Mishra V, Wallace JM, Lettenmaier DP, 2012. Relationship between hourly extreme precipitation and local air temperature in the United States, Geophys. Res. Lett., 39, L16403.Neumann, J. E., 
Price, J., Chinowsky, P., Wright, L., Ludwig, L., Streeter, R., ... \& Martinich, J. (2015). Climate change risks to US infrastructure: impacts on roads, bridges, coastal development, and urban drainage. Climatic Change, 131(1), 97-109.

Nguyen, V. T. V., Desramaut, N., \& Nguyen, T. D. (2010). Optimal rainfall temporal patterns for urban drainage design in the context of climate change. Water Science and Technology, 62(5), 11701176.

Noto, L., Lo Conti, F., La Loggia, G., \& Cannarozzo, M. (2007). Regional frequency analysis of extreme precipitation in Sicily, Italy. In Variability in space and time of extreme rainfalls, floods and droughts.

O’Gorman, P. A. (2015). Precipitation extremes under climate change. Current climate change reports, 1(2), 49-59.

Olsson, J., Willén, U., \& Kawamura, A. (2012). Downscaling extreme short-term regional climate model precipitation for urban hydrological applications. Hydrology research, 43(4), 341-351.

Panthou, G., Vrac, M., Drobinski, P., Bastin, S., \& Li, L. (2016). Impact of model resolution and Mediterranean sea coupling on hydrometeorological extremes in RCMs in the frame of HyMeX and MED-CORDEX. Climate Dynamics, 1-18.

Pereira, M.J.M.G., Fernandes, L.F.S., Macário, E.M.B., Gaspar, S.M., Pinto, J.G. (2015). Climate change impacts in the design of drainage systems: Case study of Portugal. Journal of Irrigation and Drainage Engineering, 141, 05014009.

Perry, M., Hollis, D., \& Elms, M. (2009). The generation of daily gridded datasets of temperature and rainfall for the UK. National Climate Information Centre, Met Office, Exeter, 7.

Piani, C., Haerter, J. O., \& Coppola, E. (2010). Statistical bias correction for daily precipitation in regional climate models over Europe. Theoretical and Applied Climatology, 99(1-2), 187-192.

Piani, C., Weedon, G. P., Best, M., Gomes, S. M., Viterbo, P., Hagemann, S., \& Haerter, J. O. (2010). Statistical bias correction of global simulated daily precipitation and temperature for the application of hydrological models. Journal of Hydrology, 395(3), 199-215. 
Piras, M., Mascaro, G., Deidda, R., \& Vivoni, E. R. (2014). Quantification of hydrologic impacts of climate change in a Mediterranean basin in Sardinia, Italy, through high-resolution simulations. Hydrology and Earth System Sciences, 18(12), 5201-5217.

Prein, A. F., Gobiet, A., Truhetz, H., Keuler, K., Goergen, K., Teichmann, C., ... \& Vautard, R. (2016). Precipitation in the EURO-CORDEX $0.11^{\circ}$ and $0.44^{\circ}$ simulations: high resolution, high benefits?. Climate dynamics, 46(1-2), 383-412.

Pumo, D., Caracciolo, D., Viola, F., \& Noto, L. V. (2016). Climate change effects on the hydrological regime of small non-perennial river basins. Science of The Total Environment, 542, 76-92.

Rodríguez, R., Navarro, X., Casas, M. C., Ribalaygua, J., Russo, B., Pouget, L., \& Redaño, A. (2014). Influence of climate change on IDF curves for the metropolitan area of Barcelona (Spain). International journal of climatology, 34(3), 643-654.

Semadeni-Davies, A., Hernebring, C., Svensson, G., \& Gustafsson, L. G. (2008). The impacts of climate change and urbanisation on drainage in Helsingborg, Sweden: Combined sewer system. Journal of Hydrology, 350(1), 100-113.

Simonovic, S. P., Schardong, A., Sandink, D., \& Srivastav, R. (2016). A web-based tool for the development of Intensity Duration Frequency curves under changing climate. Environmental Modelling \& Software, 81, 136-153.

Singh, R., Arya, D. S., Taxak, A. K., \& Vojinovic, Z. (2016). Potential Impact of Climate Change on Rainfall Intensity-Duration-Frequency Curves in Roorkee, India. Water Resources Management, 30(13), 4603-4616.

Saeed, S., Brisson, E., Demuzere, M., Tabari, H., Willems, P., van Lipzig, N. (2017), 'Multidecadal convection permitting climate simulations over Belgium: Sensitivity of future precipitation extremes', Atmospheric Science Letters, 18(1), 29-36

Srivastav, R. K., Schardong, A., \& Simonovic, S. P. (2014). Equidistance Quantile Matching Method for Updating IDFCurves under Climate Change. Water resources management, 28(9), 2539-2562. Tabari, H., De Troch, R., Giot, O., Hamdi, R., Termonia, P., Saeed, S., Brisson, E., Van Lipzig, N., 
Willems, P. (2016), 'Local impact analysis of climate change on precipitation extremes: are highresolution climate models needed for realistic simulations?', Hydrology and Earth System Sciences, 20, 3843-3857

Terink, W., Hurkmans, R. T. W. L., Uijlenhoet, R., Warmerdam, P. M. M., \& Torfs, P. J. J. F. (2008). Bias correction of temperature and precipitation data for regional climate model application to the Rhine basin. Wageningen Universiteit.

Tucci C. E. M., Collischonn W. (2000) Drenagem urbana e controle de erosão. Instituto de Pesquisas Hidráulicas.Universidade Federal do Rio Gande do Sul- UFRGS. Porto Alegre.

Themeß1, M. J., Gobiet, A., \& Heinrich, G. (2012). Empirical-statistical downscaling and error correction of regional climate models and its impact on the climate change signal. Climatic Change, 112(2), 449-468.

UKCIP (2013). Local Authority case studies, UK Climate Impacts Programme. http://www.ukcip.org.uk/case-studies/la-casestudies/ (accessed 20 February 2013).

Villarini, G., Smith, J. A., Baeck, M. L., Vitolo, R., Stephenson, D. B., \& Krajewski, W. F. (2011). On the frequency of heavy rainfall for the Midwest of the United States. Journal of Hydrology, 400(1), 103-120.

Viola, F., Caracciolo, D., Forestieri, A., Pumo, D., \& Noto, L. V. (2017). Annual runoff assessment in arid and semiarid Mediterranean watersheds under the Budyko's framework. Hydrological Processes, 31(10), 1876-1888.

Walsh, J. (2011). Statistical Downscaling. In NOAA Climate Services Meeting.

Wang, X., Yang, X., Liu, T., Li, F., Gao, R., Duan, L., \& Luo, Y. (2014). Trend and extreme occurrence of precipitation in a mid-latitude Eurasian steppe watershed at various time scales. Hydrological Processes, 28(22), 5547-5560.

Westra, S., Fowler, H. J., Evans, J. P., Alexander, L. V., Berg, P., Johnson, F., ... \& Roberts, N. M. (2014). Future changes to the intensity and frequency of short - duration extreme rainfall. Reviews 
863 of Geophysics, 52(3), 522-555.

864 White, R. H., \& Toumi, R. (2013). The limitations of bias correcting regional climate model inputs.

865 Geophysical Research Letters, 40(12), 2907-2912.

866 Willems, P. (2013). Revision of urban drainage design rules after assessment of climate change

867 impacts on precipitation extremes at Uccle, Belgium. Journal of Hydrology, 496, 166-177.

868 Zhou, Q., Panduro, T. E., Thorsen, B. J. \& Arnbjerg-Nielsen, K. (2013). Adaption to extreme rainfall 869 with open urban drainage system - an integrated hydrological cost benefit analysis. Environmental $870 \quad$ Management 51 (3), 586-601. 


\section{FIGURES}

872
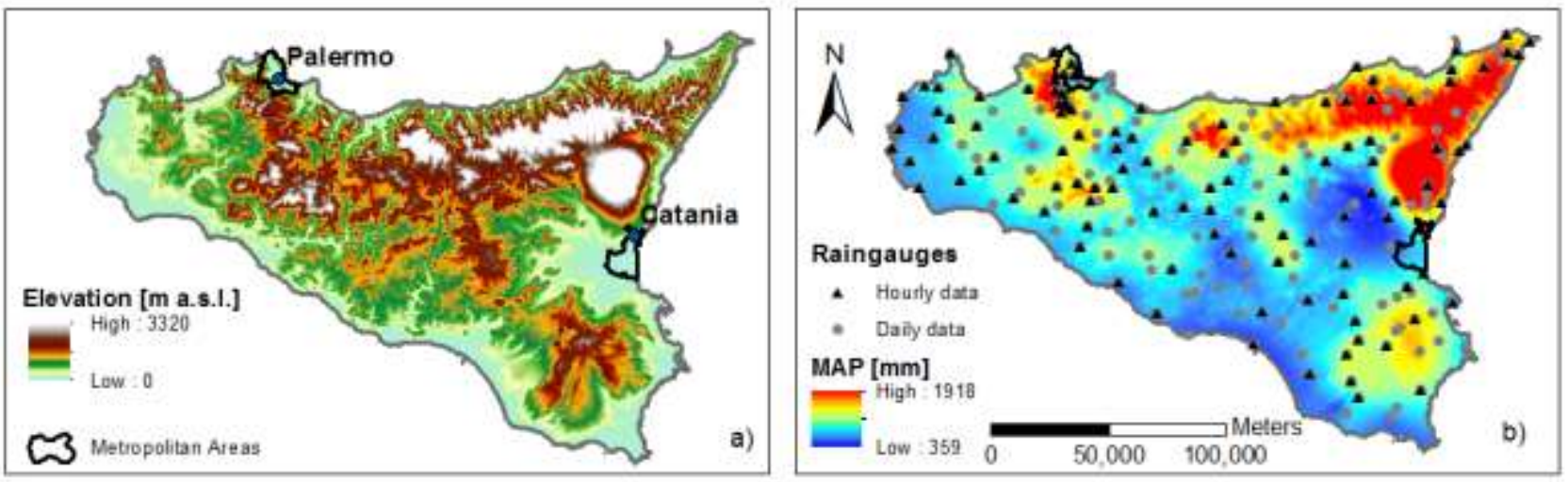

Figure. 1. Orography of Sicily (Italy) and locations of the two main metropolitan areas, Palermo and Catania (a); Mean Annual Precipitation (from Di Piazza et al., 2011) and raingauge locations (b).

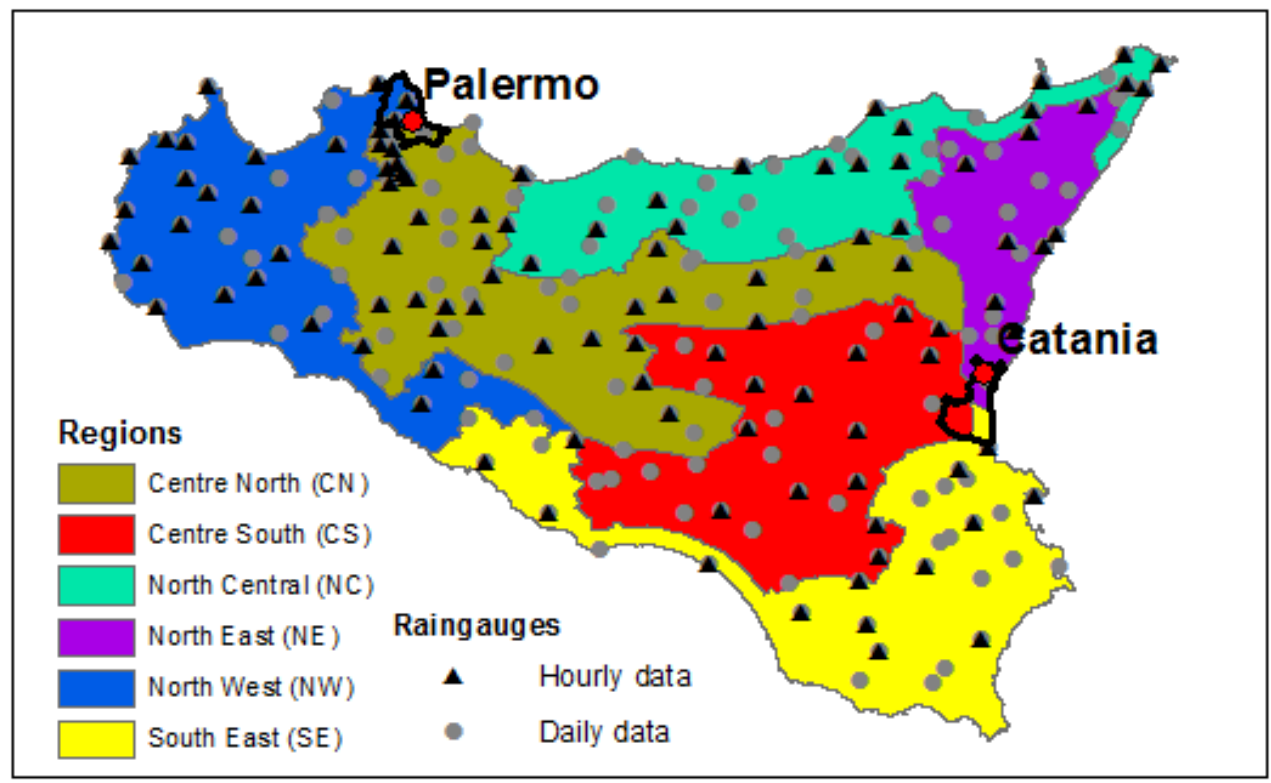

Figure. 2. The six statistically homogenous rainfall regions for Sicily (Forestieri et al., 2017). Palermo metropolitan area falls within NW and CN regions whereas Catania metropolitan areas falls within NE, CS and SE regions. 

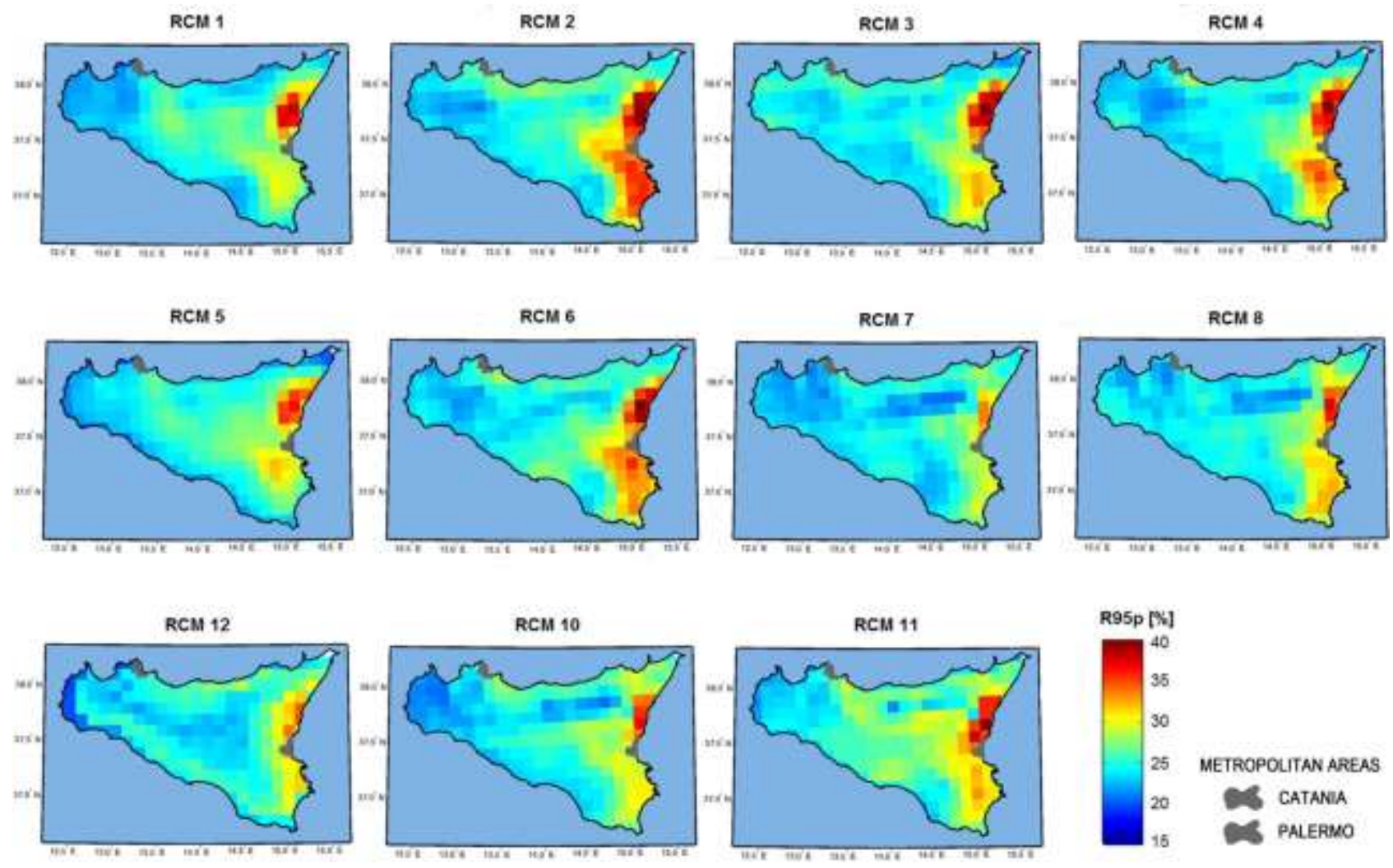

884

Figure. 3. Spatial distribution of the r95p index [\%] (see text for definition) for each RCM ensemble member. The two metropolitan areas are also shown. 
a) Before bias correction

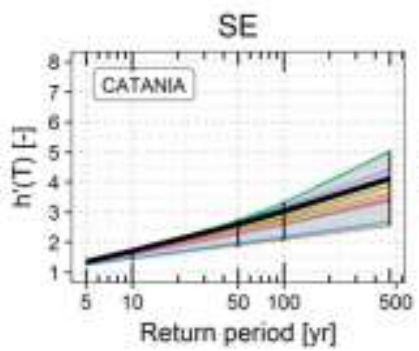

NE

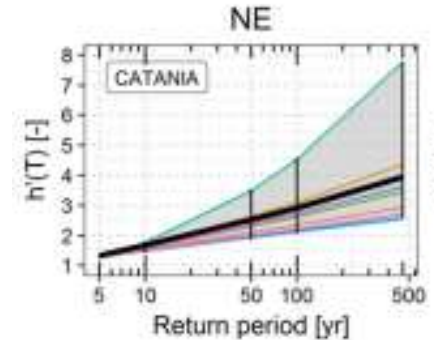

$\mathrm{CN}$

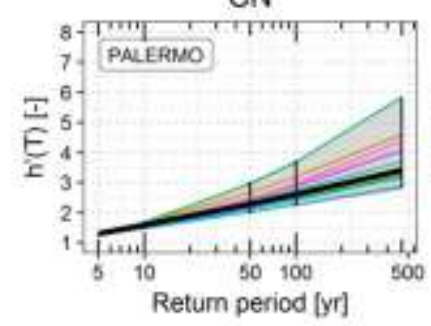

NC

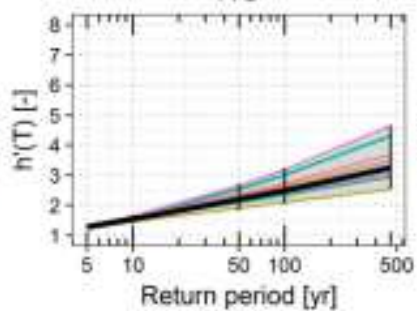

NW

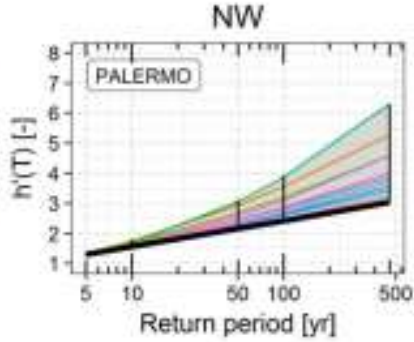

CS

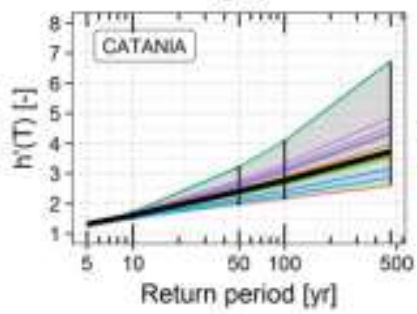

b) After bias correction
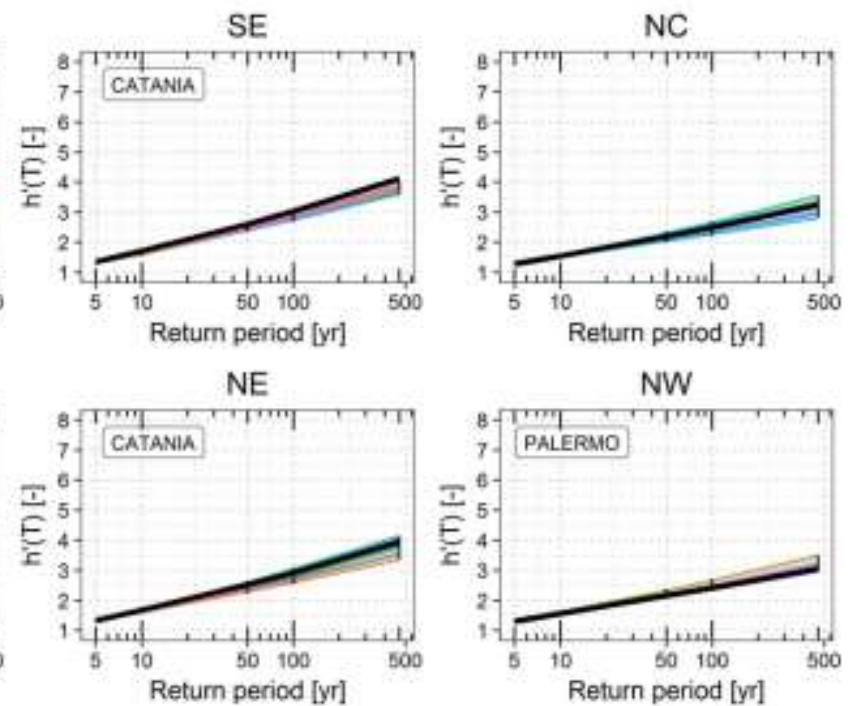

$\mathrm{CN}$

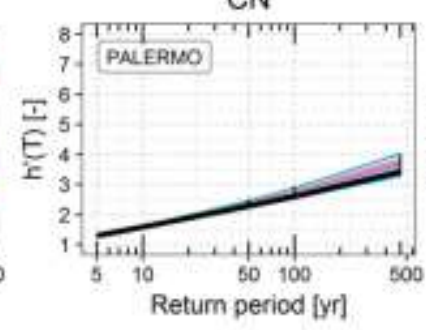

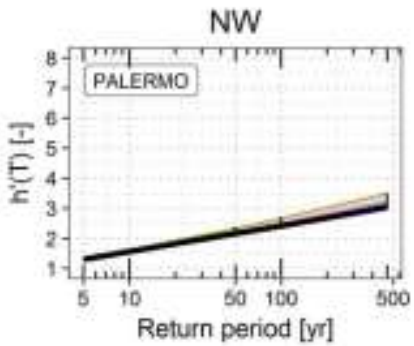

CS

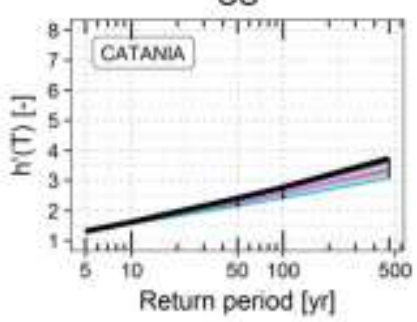

- RCM1 - RCM2 - RCM3 - RCM4 - RCM5 - RCM6 - RCM7 - RCM6 - RCM9 - RCM10 - RCM11

a) BIAS

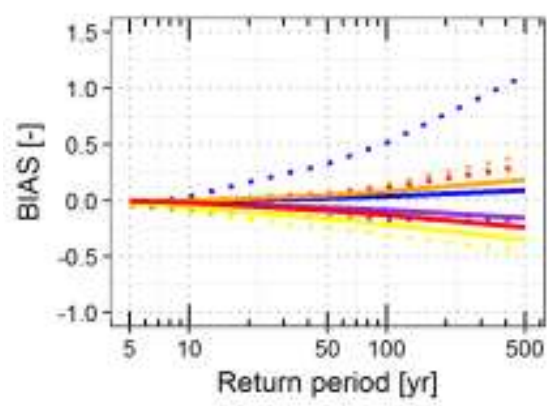

b) RMSE

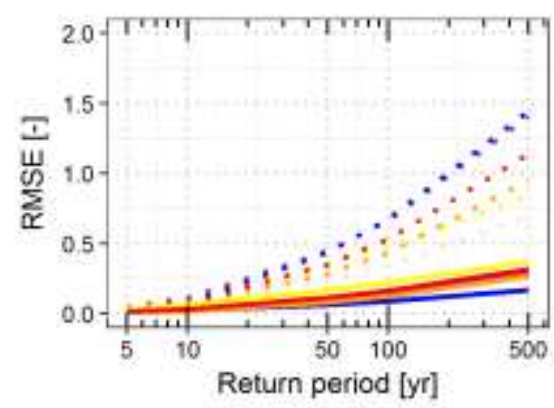

SE $\quad \mathrm{NC}-\mathrm{NE}-\mathrm{NW}-\mathrm{CN}-\mathrm{CS}$

Figure 5. Bias (a) and RMSE (b) between simulations and observation-derived quantiles as a function of return period. Dashed lines indicate the uncorrected series whereas the solid lines indicate the value obtained after bias correction. The two statistics were evaluated globally over each region for the control period (see text for details). 
a) $\mathbf{2 0 0 5 - 2 0 5 0}$

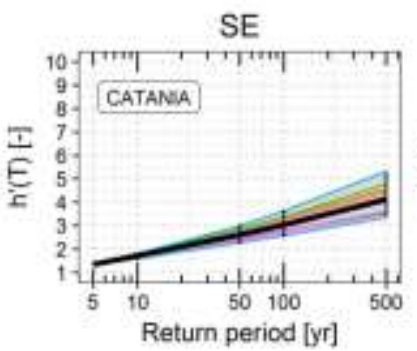

NE

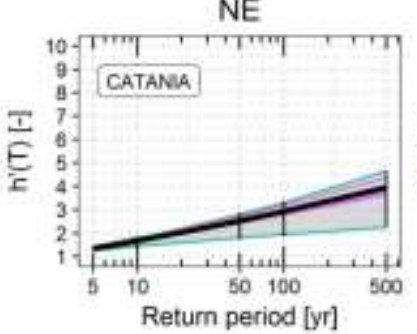

$\mathrm{CN}$

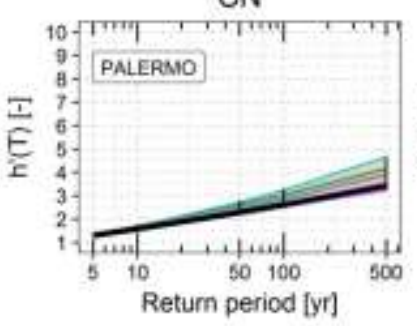

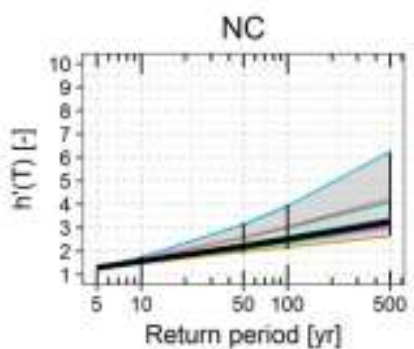

NW

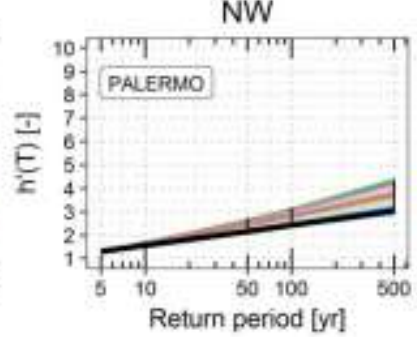

CS

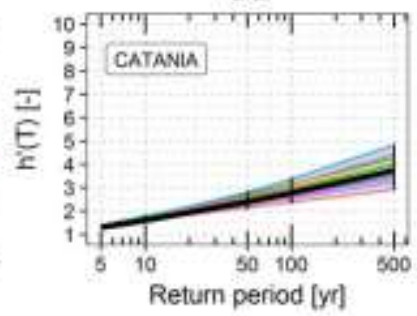

b) $2050-2100$
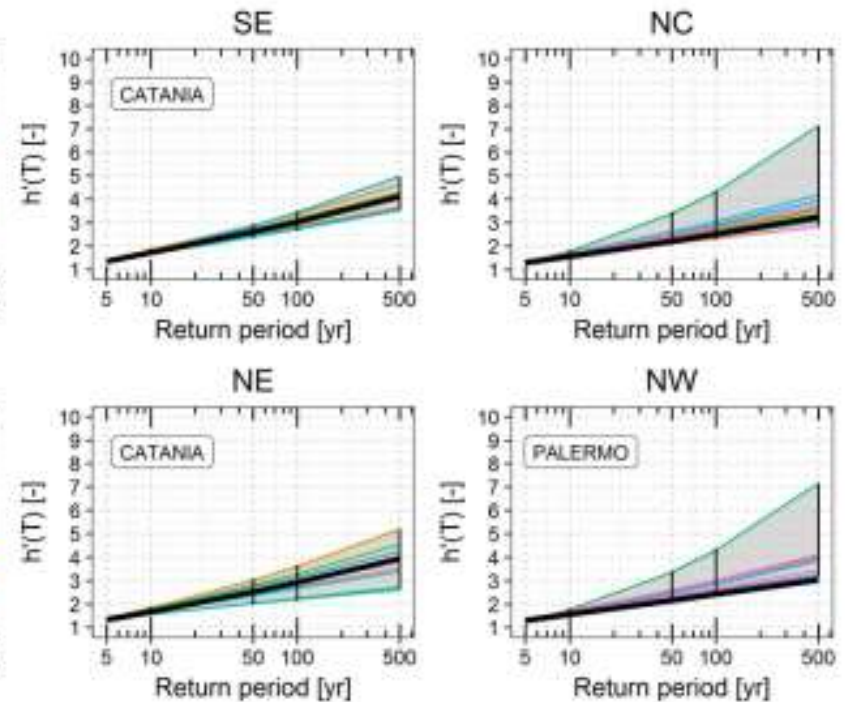

CS
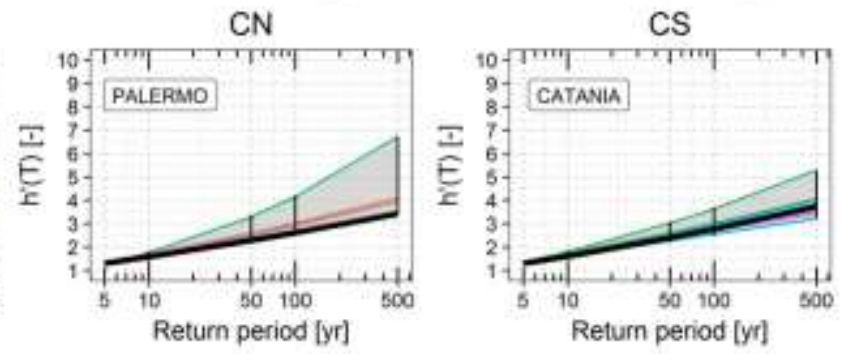

911

Figure. 6. Daily growth curves for each of the six regions and for the future project horizons (a) 2005-2050 and (b) 20502100 under the climate scenario RCP 8.5. The daily growth curve for the current period is shown for comparison (solid black line). The analysed metropolitan areas which fall within the regions are also indicated.
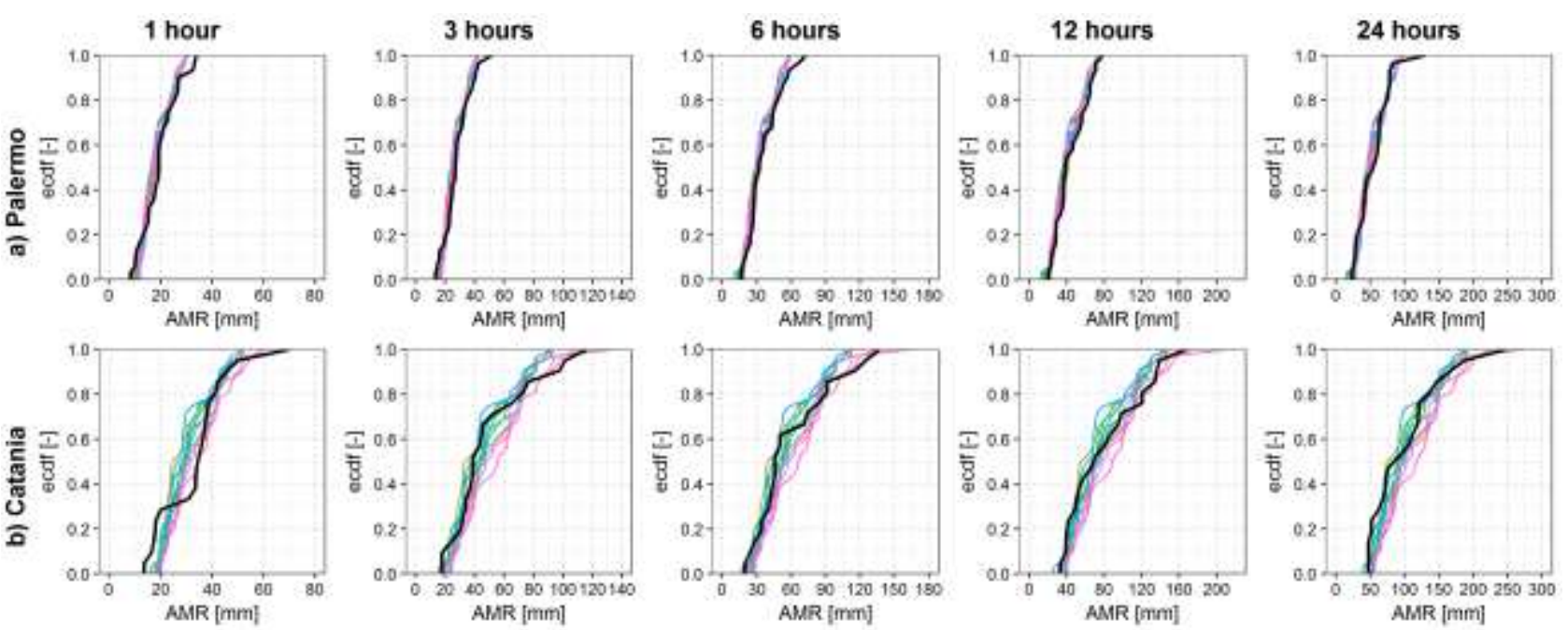

Figure. 7. Historical ECDF (1972-2003) of observed (black line) and simulated annual maxima rainfall at 1,3,6,12 and 24 durations and for two stations of the metropolitan areas of (a) Palermo and (b) Catania. 
a) 1 hour

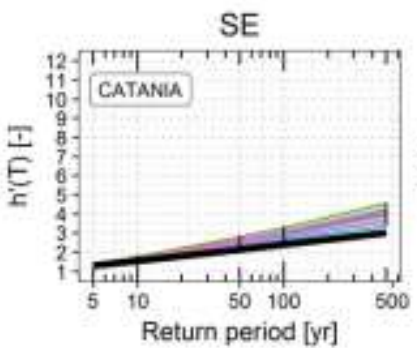

NE

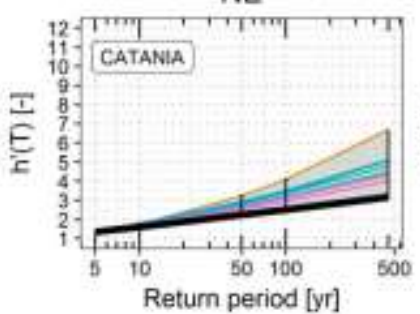

$\mathrm{CN}$

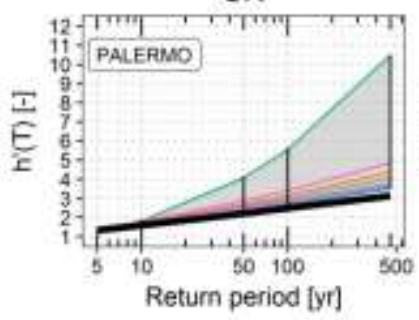

NC

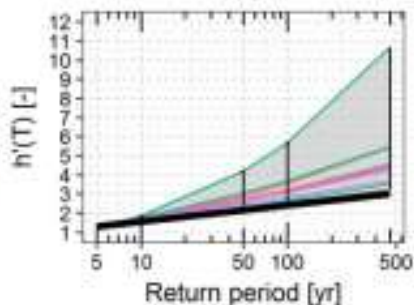

NW

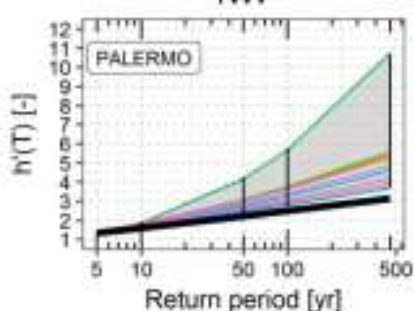

CS

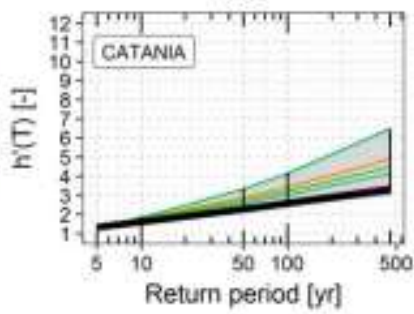

b) 12 hours
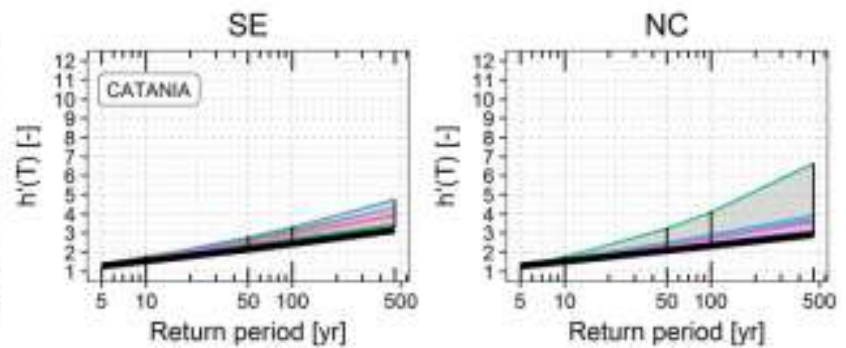

NE

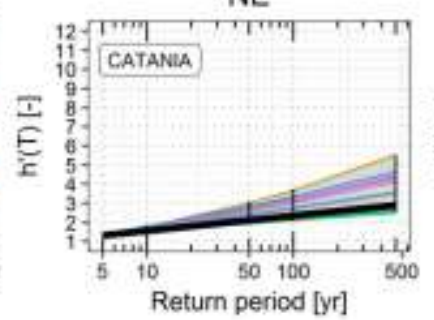

$\mathrm{CN}$

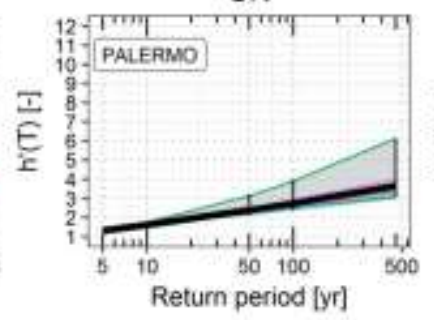

NW

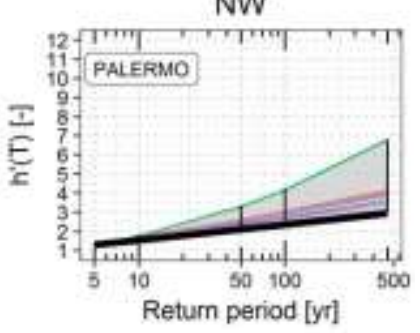

CS

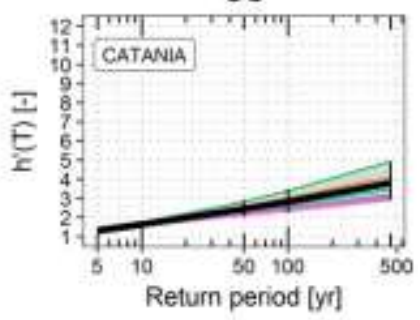$$
\text { - } \mathrm{RCM1} \text { - } \mathrm{RCM} 2 \text { - } \mathrm{RCM} 3 \text { - } \mathrm{RCM} 4 \text { - } \mathrm{RCM} 5 \text { - } \mathrm{RCM} 6 \text { - } \mathrm{RCM} 7 \text { - } \mathrm{RCMB} \text { - } \mathrm{RCM} \text { - } \mathrm{RCM} 10 \text { - } \mathrm{RCM} 11
$$

Figure. 8. Growth curves for (a) 1hour and (b) 12 hours for each of the six regions and for 2050-2100 under the climate scenario RCP 8.5. The growth curve for the current period (black line) is shown for comparison. 

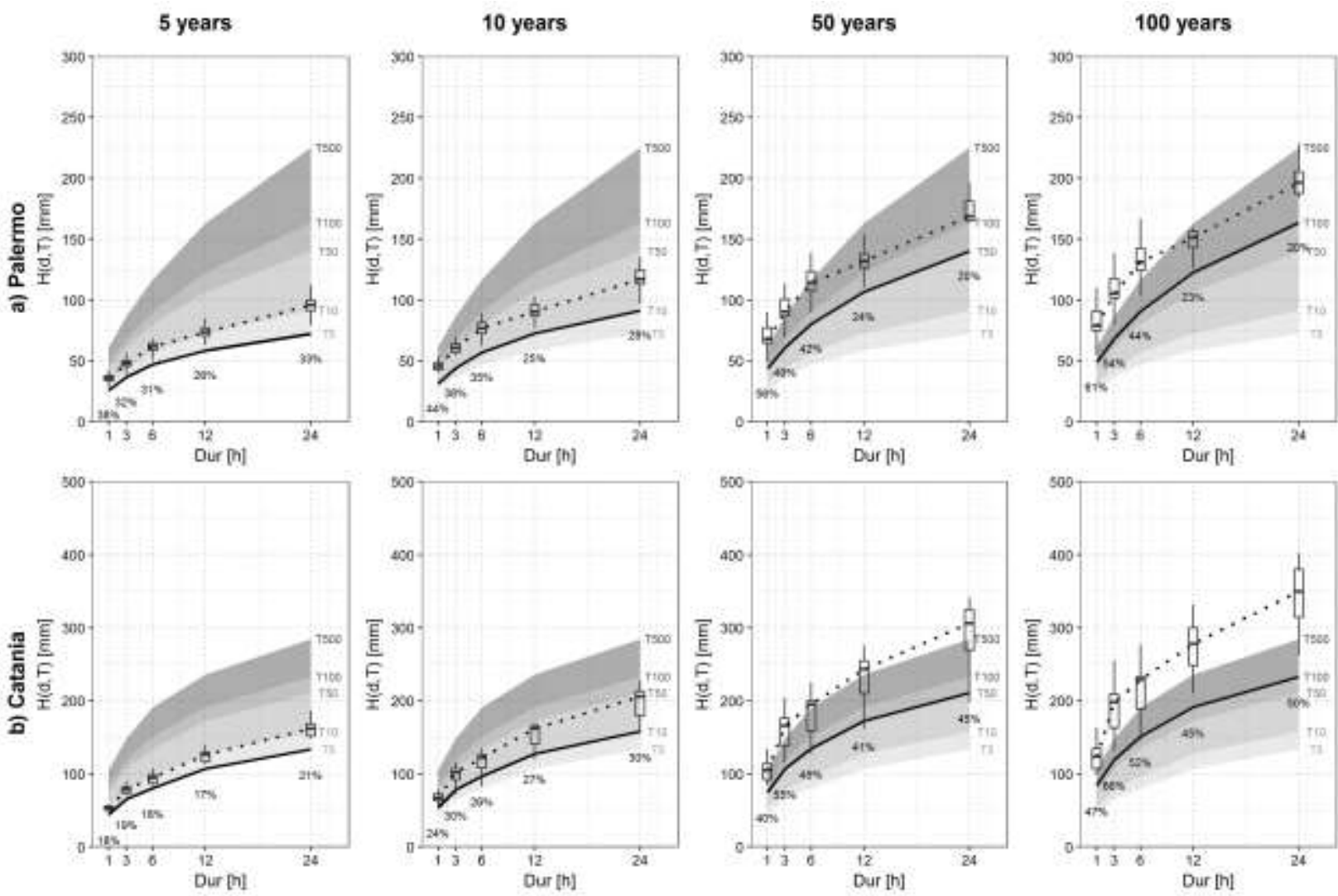

Figure 9. DDF curves at 5, 10, 50 and 100 year return periods (from first to fourth column respectively) derived from the historical data (solid black line) and from the downscaled RCM outputs (box plot), for the future horizon 2005-2050 and for Palermo (a) and Catania (b). In each panel the dashed lines depict the median of the RCMs ensemble, whereas the gradual-grey shaded areas delimit the intervals of return periods (i.e., T5, T10, T50, T100, T500) corresponding to current DDF curves. Finally, the percentage numbers indicate the relative increases compared to RCM ensemble for the different durations 

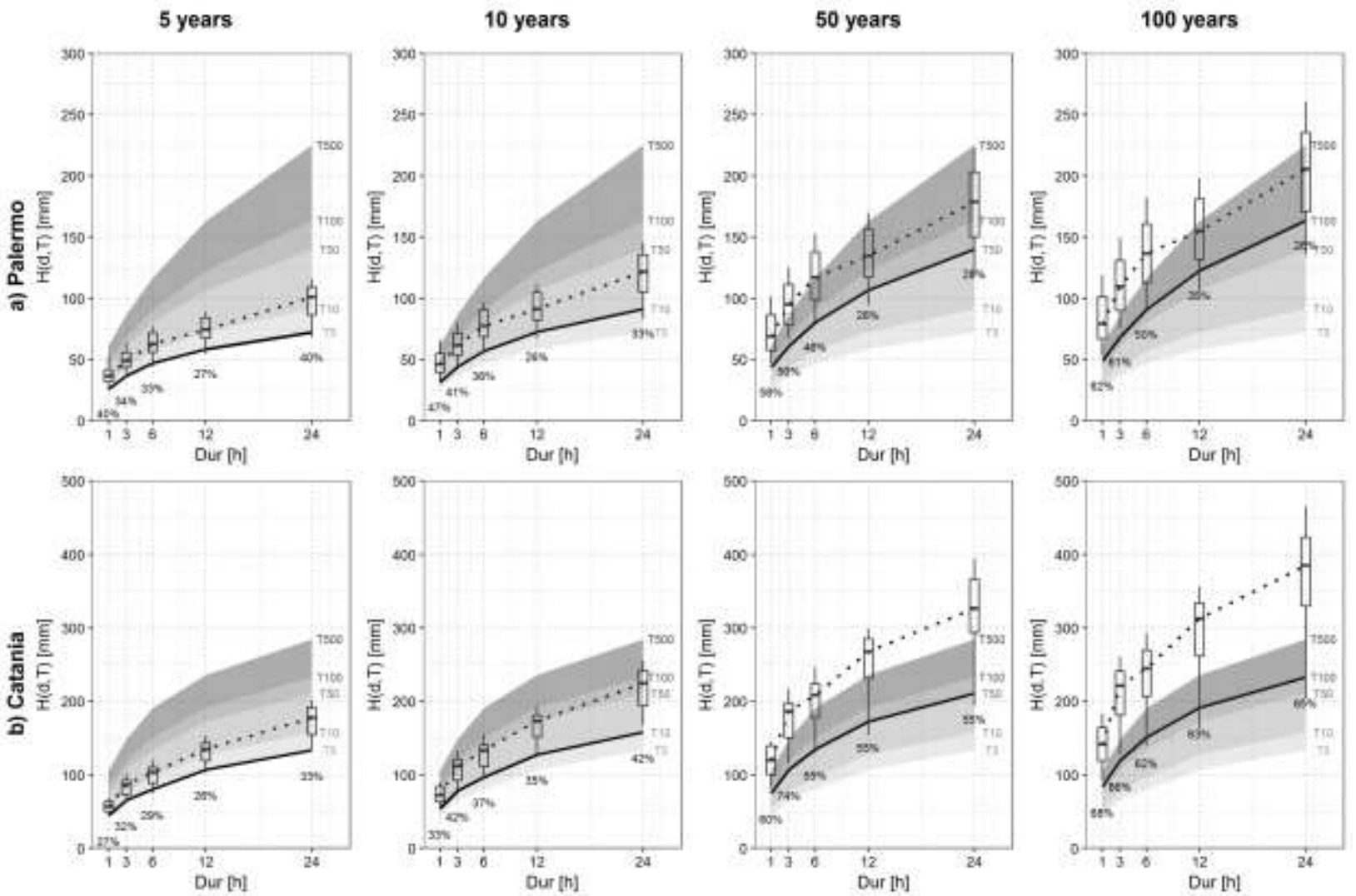

Figure 10. As for Figure 9 but for the future horizon 2050-2100. 


\section{TABLES}

Table 1. Regional climate models products from EURO-CORDEX domain used in this study.

\begin{tabular}{|c|c|c|c|c|c|}
\hline ID & Institute & RCM name & Resolution & Driving model & Driving experiment \\
\hline RCM1 & KNMI & RACMO22E & $0.11 \mathrm{deg}$ & EC-EARTH & Control/rcp85 \\
\hline RCM2 & CLMcom & CCLM4-8-17 & $0.11 \mathrm{deg}$ & CNRM-CM5-LR & Control /rcp85 \\
\hline RCM3 & CLMcom & CCLM4-8-17 & $0.11 \mathrm{deg}$ & EC-EARTH & Control /rcp85 \\
\hline RCM4 & CLMcom & CCLM4-8-17 & $0.11 \mathrm{deg}$ & MPI-ESM-LR & Control /rcp85 \\
\hline RCM5 & KNMI & RACMO22E & $0.11 \mathrm{deg}$ & EC-EARTH & Control /rcp85 \\
\hline RCM6 & CLMcom & CCLM4-8-17 & $0.11 \mathrm{deg}$ & HadGEM2-ES & Control /rcp85 \\
\hline RCM7 & SMHI & RCA4 & $0.11 \mathrm{deg}$ & CNRM-CM5 & Control /rcp85 \\
\hline RCM8 & SMHI & RCA4 & $0.11 \mathrm{deg}$ & EC-EARTH & Control /rcp85 \\
\hline RCM9 & SMHI & RCA4 & $0.11 \mathrm{deg}$ & IPSL-CM5A-MR & Control /rcp85 \\
\hline RCM10 & SMHI & RCA4 & $0.11 \mathrm{deg}$ & MPI-ESM-LR & Control /rcp85 \\
\hline RCM11 & DMI & HIRHAM5 & $0.11 \mathrm{deg}$ & EC-EARTH & Control /rcp85 \\
\hline
\end{tabular}

Table 2. Spatial mean of MAE for the historical period, for each RCM, of the uncorrected precipitation and precipitation corrected through PAR-LIN and QUANT transformations. Bold values indicate the lowest values of MAE after transformation for each RCM.

\begin{tabular}{lccc}
\hline ID & Uncorrected & PAR-LIN & QUANT \\
\hline RCM1 & 5.20 & 4.04 & $\mathbf{3 . 8 6}$ \\
RCM2 & 5.21 & 4.47 & $\mathbf{4 . 4 4}$ \\
RCM3 & 5.33 & 10.17 & $\mathbf{6 . 4 5}$ \\
RCM4 & 4.02 & $\mathbf{3 . 9 9}$ & 4.14 \\
RCM5 & 7.89 & 6.37 & $\mathbf{5 . 5 1}$ \\
RCM6 & 9.16 & $\mathbf{7 . 5 9}$ & 8.34 \\
RCM7 & 5.30 & 5.00 & $\mathbf{4 . 9 5}$ \\
RCM8 & 4.75 & 4.72 & $\mathbf{4 . 5 2}$ \\
RCM9 & 5.63 & 7.57 & $\mathbf{5 . 4 1}$ \\
RCM10 & 7.23 & $\mathbf{7 . 6 7}$ & 7.75 \\
RCM11 & 5.83 & $\mathbf{4 . 6 0}$ & 4.92 \\
\hline
\end{tabular}

Table 3. Mean coefficient of determination $\left(\mathrm{R}^{2}\right)$ between the annual maximum value of precipitation (1972-2003) at different durations.

\begin{tabular}{cc}
\hline Duration & $\mathbf{R}^{2}$ \\
\hline Day-24h & 0.76 \\
24h-12h & 0.93 \\
12h-6h & 0.91 \\
6h-3h & 0.90 \\
3h-1h & 0.84 \\
\hline
\end{tabular}


963

964 965

Table 4. Historical and future values of the quantiles of the median DDF curves and percentage changes with respect to the historical period, for Palermo and Catania

\begin{tabular}{|c|c|c|c|c|c|c|c|c|c|c|c|}
\hline \multirow{3}{*}{$\begin{array}{c}\text { Return } \\
\text { period }(T) \\
{[y r]} \\
\end{array}$} & \multirow{3}{*}{$\begin{array}{c}\text { Duration (d) } \\
\quad[\mathrm{h}]\end{array}$} & \multicolumn{5}{|c|}{ PALERMO } & \multicolumn{5}{|l|}{ CATANIA } \\
\hline & & \multirow{2}{*}{$\begin{array}{c}\begin{array}{c}\text { Historical } \\
{[\mathrm{mm}]}\end{array} \\
1972-2003\end{array}$} & \multicolumn{2}{|c|}{$\begin{array}{l}\text { RCM median } \\
{[\mathrm{mm}]}\end{array}$} & \multicolumn{2}{|c|}{$\begin{array}{c}\text { Change } \\
{[\%]}\end{array}$} & \multirow{2}{*}{$\begin{array}{c}\begin{array}{c}\text { Historical } \\
{[\mathrm{mm}]}\end{array} \\
1972-2003\end{array}$} & \multicolumn{2}{|c|}{$\begin{array}{c}\text { RCM median } \\
{[\mathrm{mm}]}\end{array}$} & \multicolumn{2}{|c|}{$\begin{array}{c}\text { Change } \\
{[\%]}\end{array}$} \\
\hline & & & $2005-2050$ & 2050-2100 & $2005-2050$ & $2050-2100$ & & $\begin{array}{l}2005- \\
2050\end{array}$ & $\begin{array}{l}2050- \\
2100\end{array}$ & $\begin{array}{l}2005- \\
2050\end{array}$ & $\begin{array}{l}2050- \\
2100\end{array}$ \\
\hline \multirow{5}{*}{5} & 1 & 25.96 & 35.75 & 36.30 & 37.69 & 39.81 & 44.56 & 52.61 & 56.75 & 18.06 & 27.36 \\
\hline & 3 & 36.44 & 48.02 & 48.74 & 31.77 & 33.76 & 65.68 & 78.05 & 86.47 & 18.83 & 31.66 \\
\hline & 6 & 46.97 & 61.76 & 62.68 & 31.48 & 33.44 & 80.43 & 94.60 & 103.63 & 17.61 & 28.84 \\
\hline & 12 & 58.51 & 73.54 & 74.41 & 25.69 & 27.17 & 107.19 & 125.76 & 135.35 & 17.32 & 26.27 \\
\hline & 24 & 72.24 & 95.95 & 101.13 & 32.81 & 39.98 & 133.46 & 161.94 & 177.68 & 21.34 & 33.14 \\
\hline \multirow{5}{*}{10} & 1 & 31.35 & 45.08 & 46.09 & 43.78 & 47.00 & 53.91 & 66.96 & 71.91 & 24.20 & 33.39 \\
\hline & 3 & 43.81 & 60.54 & 61.60 & 38.19 & 40.60 & 78.48 & 102.04 & 111.61 & 30.02 & 42.21 \\
\hline & 6 & 56.88 & 76.88 & 77.54 & 35.15 & 36.31 & 96.97 & 121.97 & 132.99 & 25.78 & 37.14 \\
\hline & 12 & 72.41 & 90.34 & 91.37 & 24.75 & 26.18 & 127.71 & 161.80 & 172.84 & 26.69 & 35.34 \\
\hline & 24 & 91.32 & 117.06 & 121.78 & 28.19 & 33.36 & 157.97 & 205.67 & 224.53 & 30.19 & 42.13 \\
\hline \multirow{5}{*}{50} & 1 & 43.52 & 67.70 & 68.74 & 55.57 & 57.96 & 74.91 & 104.72 & 119.98 & 39.79 & 60.16 \\
\hline & 3 & 60.76 & 90.29 & 94.83 & 48.60 & 56.06 & 106.94 & 165.70 & 186.18 & 54.95 & 74.10 \\
\hline & 6 & 80.25 & 113.94 & 117.18 & 41.98 & 46.02 & 134.57 & 195.09 & 208.24 & 44.98 & 54.75 \\
\hline & 12 & 106.59 & 131.89 & 134.63 & 23.73 & 26.30 & 172.52 & 243.32 & 267.63 & 41.04 & 55.13 \\
\hline & 24 & 140.11 & 168.64 & 178.89 & 20.36 & 27.68 & 210.88 & 306.36 & 326.75 & 45.27 & 54.94 \\
\hline \multirow{5}{*}{100} & 1 & 48.82 & 78.55 & 78.89 & 60.88 & 61.58 & 84.03 & 123.34 & 141.30 & 46.78 & 68.16 \\
\hline & 3 & 68.27 & 104.98 & 109.74 & 53.78 & 60.76 & 119.19 & 198.14 & 221.24 & 66.24 & 85.62 \\
\hline & 6 & 90.80 & 131.17 & 136.34 & 44.45 & 50.15 & 151.05 & 228.99 & 244.56 & 51.60 & 61.91 \\
\hline & 12 & 122.54 & 151.33 & 154.79 & 23.49 & 26.32 & 191.53 & 277.98 & 312.89 & 45.13 & 63.36 \\
\hline & 24 & 163.62 & 196.50 & 205.60 & 20.09 & 25.65 & 233.11 & 349.60 & 384.83 & 49.97 & 65.08 \\
\hline
\end{tabular}

Table 5. Historical and future changes of the parameters $a$ and $n$ of the DDF curve equations with respect to the historical period, for the stations located in Palermo and Catania

\begin{tabular}{|c|c|c|c|c|c|c|c|c|c|c|c|}
\hline & & PALERM & & & & & CATANIA & & & & \\
\hline \multirow{2}{*}{$\begin{array}{c}\text { Return } \\
\text { period }(\mathrm{T}) \\
{[\mathrm{yr}]} \\
\end{array}$} & & Historical & \multicolumn{2}{|c|}{ RCM median } & \multicolumn{2}{|c|}{ Change [\%] } & \multirow{2}{*}{$\begin{array}{c}\text { Historical } \\
1972-2003\end{array}$} & \multicolumn{2}{|c|}{ RCM median } & \multicolumn{2}{|c|}{ Change [\%] } \\
\hline & & $1972-2003$ & 2005-2050 & 2050-2100 & $2005-2050$ & $2050-2100$ & & $2005-2050$ & 2050-2100 & $2005-2050$ & $2050-2100$ \\
\hline \multirow{2}{*}{5} & $\mathbf{a}$ & 25.89 & 35.11 & 35.36 & 35.62 & 36.59 & 44.47 & 52.29 & 56.92 & 17.58 & 28.00 \\
\hline & $\mathbf{n}$ & 0.325 & 0.309 & 0.317 & -5.10 & -2.46 & 0.346 & 0.352 & 0.353 & 1.47 & 1.85 \\
\hline \multirow{2}{*}{10} & $\mathbf{a}$ & 30.91 & 44.50 & 45.15 & 43.99 & 46.08 & 53.77 & 67.40 & 72.82 & 25.30 & 35.40 \\
\hline & $\mathbf{n}$ & 0.340 & 0.297 & 0.300 & -12.59 & -11.65 & 0.340 & 0.350 & 0.352 & 2.79 & 3.26 \\
\hline \multirow{2}{*}{50} & $\mathbf{a}$ & 42.05 & 67.14 & 68.54 & 59.66 & 62.98 & 74.86 & 108.53 & 123.88 & 44.98 & 65.49 \\
\hline & $\mathrm{n}$ & 0.372 & 0.284 & 0.292 & -23.63 & -21.48 & 0.329 & 0.330 & 0.308 & 0.15 & -6.38 \\
\hline \multirow{2}{*}{100} & $\mathbf{a}$ & 46.85 & 77.79 & 79.07 & 66.05 & 68.77 & 84.06 & 129.41 & 146.41 & 53.96 & 74.18 \\
\hline & $\mathbf{n}$ & 0.385 & 0.283 & 0.292 & -26.37 & -24.14 & 0.325 & 0.317 & 0.306 & -2.59 & -5.76 \\
\hline
\end{tabular}

